\title{
Divergent Synthesis of Densely Substituted Arenes and Pyri- dines via Cyclotrimerization Reactions of Alkynyl Triazenes
}

\author{
Jin-Fay Tan, ${ }^{[\mathrm{a}]}$ Carl Thomas Bormann, ${ }^{[\mathrm{b}]}$ Florian G. Perrin, ${ }^{[\mathrm{b}]}$ F. Mark Chadwick, ${ }^{[\mathrm{b}]}$ Kay Severin, ${ }^{* \mathrm{~b}]} \mathrm{Ni}-$ \\ colai Cramer*[a] \\ [a] Laboratory of Asymmetric Catalysis and Synthesis, Institute of Chemical Sciences and Engineering, Ecole Polytechnique \\ Fédérale de Lausanne (EPFL), 1015 Lausanne, Switzerland. \\ ${ }^{[b]}$ Laboratory of Supramolecular Chemistry, Institute of Chemical Sciences and Engineering, Ecole Polytechnique Fédérale \\ de Lausanne (EPFL), 1015 Lausanne, Switzerland.
}

\begin{abstract}
Densely functionalized fused aromatic triazenes can be prepared by [2 + $2+2]$ cyclotrimerization reactions of 1alkynyl triazenes. The Cp*Ru-catalyzed cyclization proceeds well both with simple alkynyl triazenes and tethered 1-diynyl triazenes. Attractively, the methodology can be extended to pyridine synthesis by replacing an alkyne with a nitrile. The reaction is regioselective and yields the sterically more hindered product. The triazene group precisely installed on the synthesized aryl and pyridyl ring is a highly versatile moiety, which is effortlessly converted into the most important and frequently used functional aryl substituents, including fluorides. It is also suited for intramolecular transformations to afford a variety of valuable heterocycles. The coordination chemistry of alkynyl triazenes and $\mathrm{Cp} * \mathrm{RuCl}$ was studied, and led to the structural characterization of a Cp*RuCl( $\eta^{2}$-alkyne) complex, a Cp*RuCl $\left(\eta^{4}\right.$-cyclobutadiene) complex, and an unusual dinuclear Ru complex with a bridging tetramethylfulvene ligand. Complexes of this type are potentially involved in catalyst deactivation pathways.
\end{abstract}

\section{Introduction}

Aryl triazenes have garnered great attention over the last decades. Some triazenes display valuable biological activities and for instance are used as anti-cancer agents. ${ }^{1,2}$ A very large portion of their high synthetic value stems from their unique property as a stable aryl diazonium surrogate. In this respect, they represent a platform intermediate that can be easily transformed into many functional groups. Synthetic applications range from natural product synthesis, ${ }^{3}$ heterocycle synthesis, ${ }^{4,5}$ linkers in solid-phase synthesis, ${ }^{6}$ to materials. ${ }^{7}$ The aryl diazonium functionality is revealed under acidic conditions and can be elaborated into numerous functional groups upon interception with nucleophiles. ${ }^{1,8-11}$ However, the synthetic access to such aryl triazenes requires an already appropriately functionalized aryl precursor (Scheme 1). The most frequently used procedure involves the diazotization of an aniline substrate and its subsequent coupling to a secondary amine. ${ }^{12}$ Alternative methods use aryl magnesium salts and azides ${ }^{13}$ or aminodiazotates ${ }^{14}$ as partners. The requirement of a functionalized substrate limits exploitation of the triazene platform, particularly if the targeted functionalized substrate is not available or features a complex substitution pattern. For further exploitation of the synthetic potential of aryl triazenes, complementary methods without the requirement of pre-functionalized arenes would be highly desirable.
Scheme 1: Access to Aryl \& Heteroaryl Triazenes and their use as Versatile Platform Intermediates.

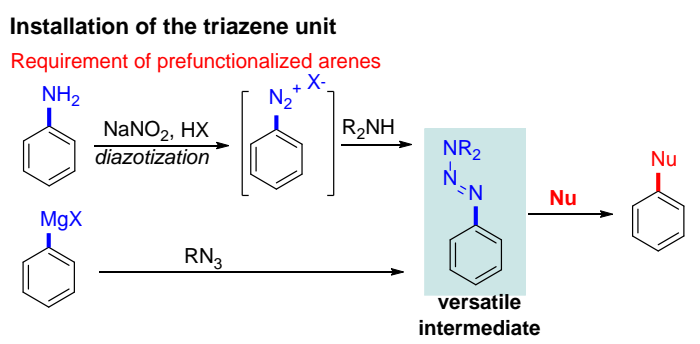

This work: Construction of the aryl unit

- high regio selectivity - divergent elaboration reactions - arenes \& pyridines - alkynyl triazene coordination chemistry

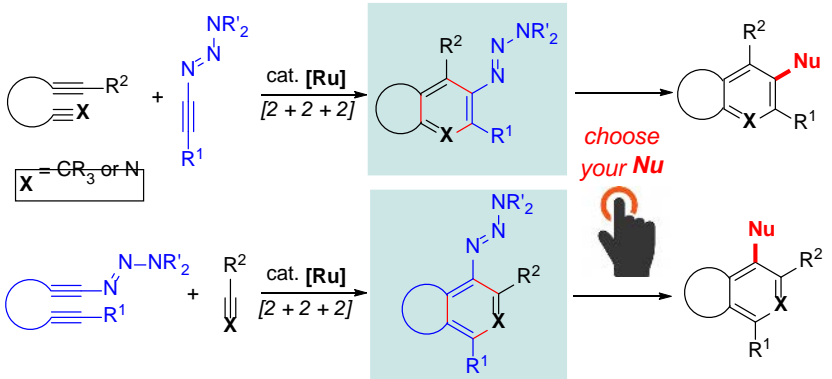

Transition-metal catalyzed [ $2+2+2]$ cyclotrimerizations are a powerful tool to construct complex densely substituted arenes from three simple alkynes. ${ }^{15-19}$ Replacement of an alkyne by a nitrile opens an attractive avenue to highly valued pyridines. ${ }^{20-}$ ${ }^{22}$ Fueled by our recently reported access to 1-alkynyl triazenes, ${ }^{14}$ the reactivity profile of this particular alkyne having properties related to ynamides ${ }^{23 f}$ was explored. ${ }^{23}$ Intrigued by the compatibility of 1 -alkynyl triazenes with $\mathrm{Ru}^{\mathrm{II}}$-catalysts for 
enantioselective [2 + 2] cycloadditions, ${ }^{23 c}$ we investigated the possibility to prepare highly elaborated aryl and heteroaryl triazenes by Ru-catalyzed cyclotrimerization reactions (Scheme 1 ). Noteworthy, combined with nitriles, the reactions would provide a unique access to 3-triazenyl-substituted pyridines. Subsequent elaboration of the triazene unit would enable a general divergent functionalization strategy targeting the 3-position of pyridines. Frequently, functionalizations of the 3-position of pyridines are sluggish and challenging for $S_{E} A r$ as well as $S_{N} A r-$ type reactions. ${ }^{24}$

In general, the envisioned bicyclic arenes and pyridines with a triazenyl group are highly valuable scaffolds. Such fused aryl and pyridyl systems are frequently occurring motifs in natural products and biologically active molecules (Figure 1 ). ${ }^{25}$ The regioselectively installed triazenyl moiety can be easily elaborated by a myriad of methods, offering late stage functional group modifications on these important frameworks in a divergent fashion. Besides the introduction of many different nucleophiles, the triazenyl unit can as well engage in intramolecular cyclizations to deliver several heterocyclic systems. ${ }^{4,5}$
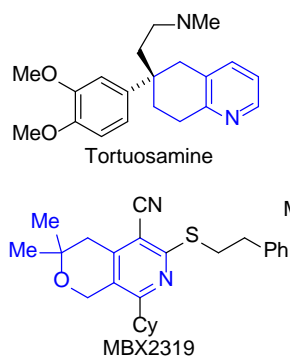

(antimicrobial potentiator)

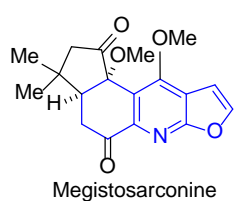

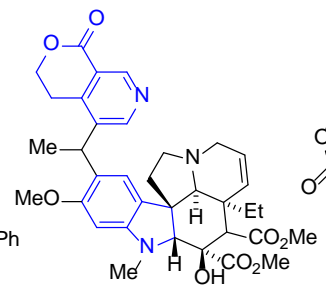

Vindogentianine

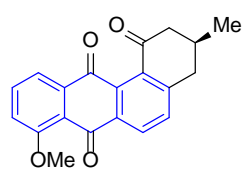

(+)-Rubiginone B2
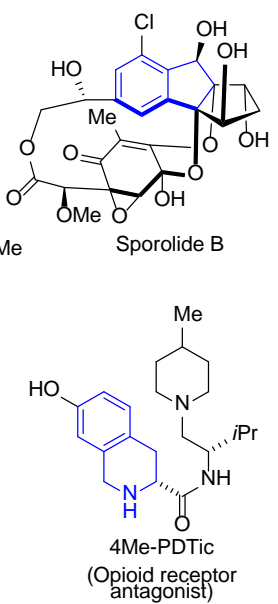

Figure 1. Selected examples of fused-arene and fused-pyridine heterocyclic compounds and natural products.

\section{Results and Discussion}

We first conducted a compatibility check to gauge the stability of the alkynyl triazene in the presence of the most common cyclotrimerization catalysts. ${ }^{16-19}$ For this purpose, the synthesis of isoindoline 3aa from the reaction between diyne 1a and alkynyl triazene 2a was targeted (Table 1 ). Under $\mathrm{Ni}^{0}$ catalysis, ${ }^{17}$ the alkynyl triazene is unstable and decomposes without formation of a defined product (Entry 1). Along the same lines, $\mathrm{Fe}^{\mathrm{II}}$ and $\mathrm{Pd}^{0}$ were not competent for the envisioned cyclotrimerization. ${ }^{18}$ Again, decomposition of 2a was observed (Entries 2 and 3). In contrast, different $\mathrm{Rh}^{\mathrm{I}}$ catalysts were able to effect the cyclization, ${ }^{19}$ giving desired 3aa in 15-35\% yield (Entries 4-6). However, in all three cases, homotrimerization of 1a could not be mitigated and was the major reaction pathway. Gratifyingly, exposure of the substrates to $\mathrm{Cp} * \mathrm{Ru}(\mathrm{cod}) \mathrm{Cl}$, a $\mathrm{Ru}^{\mathrm{II}}$ complex introduced by Yamamoto ${ }^{16}$ for $[2+2+2]$ cycloadditions, provided 3aa at ambient temperature in $50 \%$ yield (Entry 7$)$. The formation of di- and trimerization products $\mathbf{x}$ and $\mathbf{y}$ from the tethered diyne 1a could be effectively suppressed in this case by its slow addition to the reaction mixture. Ruthenium complexes lacking the $\mathrm{Cp}^{*}$ ligand were not competent for the cyclization (Entries 8 and 9). The usage of $\left[\mathrm{Cp} * \mathrm{RuCl}_{2}\right]_{2}$ improved the yield of 3aa to $74 \%$ (Entry 10). With prolongation of the addition period of 1a, this complex allowed for a full and clean conversion of 2a to 3aa with a reduced catalyst loading (Entry 13).

Table 1: Optimization of the Fused Aryl Triazene Formation $^{\mathrm{a}}$

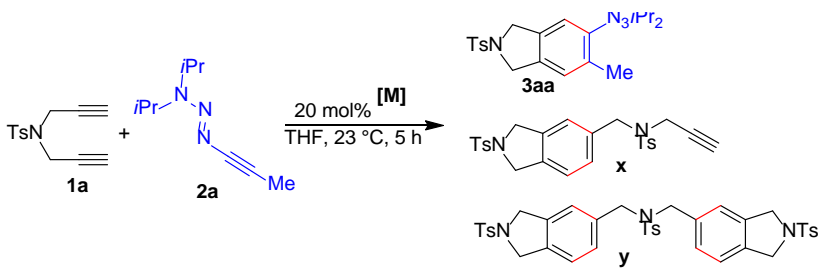

\begin{tabular}{|c|c|c|c|c|}
\hline Entry & [M] & \% conv. ${ }^{b}$ & $\% 3 \mathbf{a a}^{\mathrm{b}}$ & $\% x+y^{b}$ \\
\hline $1^{\mathrm{c}}$ & $\mathrm{Ni}(\mathrm{cod})_{2} /$ xantphos & $>95$ & - & - \\
\hline 2 & $\mathrm{FeCl}_{2}$ / dppe / Zn & 34 & $<5$ & $<5$ \\
\hline $3^{\mathrm{c}, \mathrm{d}}$ & $\mathrm{Pd}_{2}(\mathrm{dba})_{3} / \mathrm{PPh}_{3}$ & 65 & $<5$ & $<5$ \\
\hline 4 & {$\left[\mathrm{Rh}(\mathrm{cod})_{2}\right] \mathrm{BF}_{4} /$ binap } & 47 & 35 & 61 \\
\hline 5 & {$\left[\mathrm{Rh}(\mathrm{cod})_{2}\right] \mathrm{BF}_{4} /$ Segphos } & 25 & 15 & 60 \\
\hline 6 & $\mathrm{Rh}(\mathrm{PPh})_{3} \mathrm{Cl}$ & 26 & 20 & 75 \\
\hline 7 & Cp*RuCl(cod)Cl & 68 & 50 & 4 \\
\hline 8 & {$\left[(\text { Cymene }) \mathrm{RuCl}_{2}\right]_{2}$} & $<5$ & $<5$ & 40 \\
\hline 9 & {$\left[\mathrm{Ru}(\operatorname{cod}) \mathrm{Cl}_{2}\right]_{\mathrm{n}}$} & 0 & - & - \\
\hline 10 & $\left(\mathrm{Cp} * \mathrm{RuCl}_{2}\right)_{2}$ & 94 & 74 & 12 \\
\hline $11^{\mathrm{e}}$ & $\left(\mathrm{Cp} * \mathrm{RuCl}_{2}\right)_{2}$ & 80 & 64 & - \\
\hline $12^{\mathrm{f}}$ & $\left(\mathrm{Cp} * \mathrm{RuCl}_{2}\right)_{2}$ & 47 & 30 & - \\
\hline $13^{e, g}$ & $\left(\mathrm{Cp} * \mathrm{RuCl}_{2}\right)_{2}$ & $>95$ & $82^{\mathrm{h}}$ & - \\
\hline
\end{tabular}

a Conditions: $0.1 \mathrm{mmol}$ 2a, $20 \mathrm{~mol} \%$ [M], $30 \mathrm{~mol} \%$ additive(s), slow addition of $1 \mathrm{a}$ over $5 \mathrm{~h}, 0.1 \mathrm{M}$ in THF. [b] Determined by ${ }^{1} \mathrm{H}-$ NMR with an internal standard; conversion of 2a. [c] PhMe was used as solvent. [d] $110^{\circ} \mathrm{C}$. [e] With 5 mol\% cat. [f] With 2.5 mol\% cat. [g] Slow addition of 1a over $10 \mathrm{~h}$. [h] Isolated yield.

The scope of the reaction was subsequently evaluated with the optimized condition (Scheme 2). A series of 1,6-diynes containing typical hetero atom or carbon tethers reacted well, forming the desired arenes 3aa-3ga in good yields. Notably, basic nitrogen atoms (3ba) caused no problem. The use of 1,7-diynes allowed the construction of larger ring systems such as tetrahydroisoquinoline 3ha, 5,10-dihydroanthracene 3ia and isochroman 3ja. Despite considerable distance of the heteroatom in the tether, the cyclotrimerization proceeds in a regioselective manner. The triazenyl group is preferentially placed meta to benzylic nitrogen or oxygen atom. Using a diyne with two internal alkynes $\left(\mathrm{R}^{1}, \mathrm{R}^{2}=\mathrm{Me}\right)$ provided hexa-substituted arene 3ka. Unsymmetrical diyne substrates reacted and gave arene products 3la-3na. Remarkably, the $\mathrm{R}^{1}$ substituent is preferentially placed ortho to the triazenyl group. This seems to be counterintuitive since the triazenyl group is sterically more demanding than the methyl residue. The regioselectivity is contrasting with the usually observed meta-selectivity for these constellations, ${ }^{16 \mathrm{~b}}$ which may be explained by the electronic influence of the triazenyl moiety on the alkyne. Concerning the alkynyl triazene, its isopropyl groups can be swapped for bulkier cyclohexyl substituents (3ab), maintaining efficiency of the transformation. Moreover, the cyclization proceeded as well with alkynes having 
larger substituents $\mathrm{R}^{3}$ such as butyl (3ac), cyclopropyl (3ad) and phenyl (3ae).

Scheme 2: Scope for the Ru-Catalyzed Synthesis of Aryl Triazenes. $^{\mathrm{a}}$

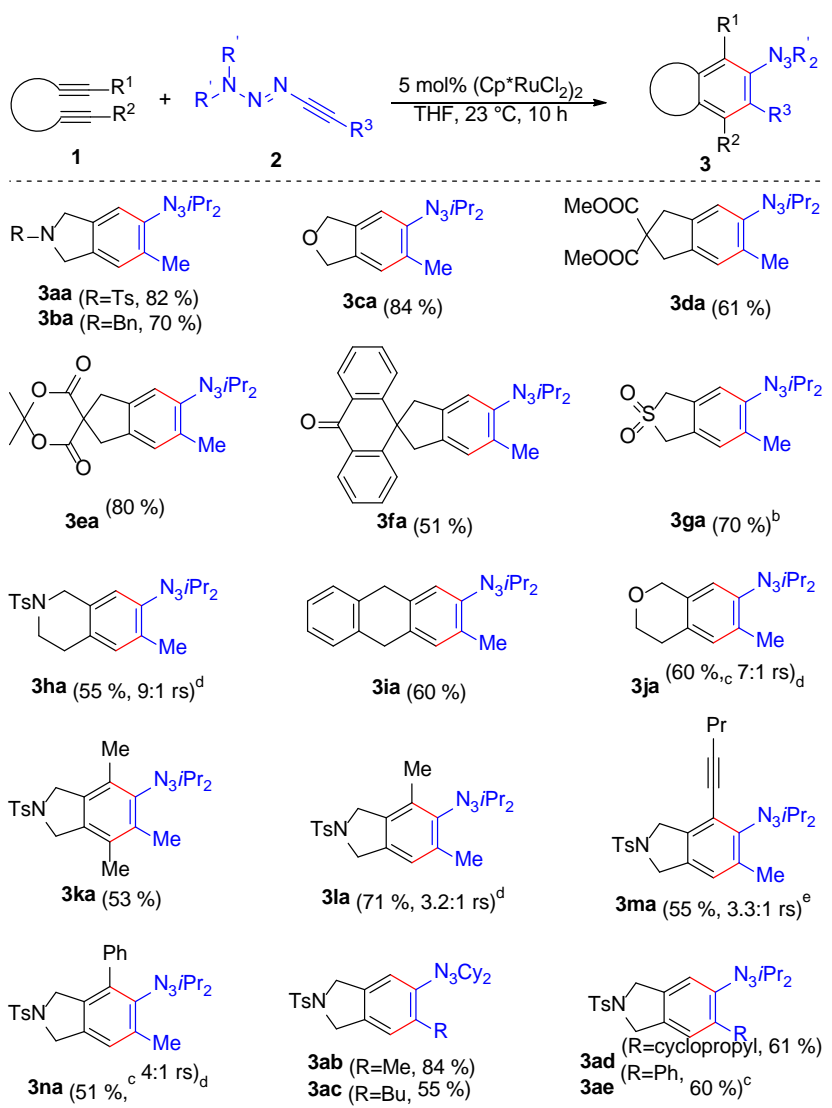

${ }^{a}$ Conditions: $0.1 \mathrm{mmol}$ 2, $0.15 \mathrm{mmol} \mathrm{1,} 5 \mathrm{~mol} \%\left(\mathrm{Cp}^{*} \mathrm{RuCl}_{2}\right)_{2}$, $0.1 \mathrm{M}$ in THF, isolated yields. ${ }^{\mathrm{b}} 0.15 \mathrm{mmol} \mathbf{1 g}, 0.1 \mathrm{mmol} 2 \mathrm{2a}, 5$ mol\% $\left(\mathrm{Cp}^{*} \mathrm{RuCl}_{2}\right)_{2}$, at $60{ }^{\circ} \mathrm{C}$ for $18 \mathrm{~h} .{ }^{\mathrm{c}} 10 \mathrm{~mol} \%\left(\mathrm{Cp} * \mathrm{RuCl}_{2}\right)_{2}{ }^{\mathrm{d}}$ Ratio of regioisomers determined by ${ }^{1} \mathrm{H}$ NMR. ${ }^{\mathrm{e}}$ Ratio determined from isolated isomers.

After developing a catalytic system for the installation of the triazenyl group distal to the ring fusion, it piqued our interest to examine the possibility to access arenes having this versatile group proximal to the ring fusion. This maneuver would further enhance the synthetic utility of the methodology in complex molecule synthesis. We conceived that a related [ $2+2+2]$ cycloaddition between a tethered 1-diynyl triazene $\mathbf{4}$ and an alkyne 5 would suit well this purpose (Scheme 3). To our delight, the same catalyst, $\left[\mathrm{Cp} * \mathrm{RuCl}_{2}\right]_{2}$, allowed conversion of 1-(1,6diynynl) triazene $\mathbf{4 a}$ and pent-1-yne into aryl triazene $\mathbf{6 a a}$ in 93 $\%$ in less than two hours. Notably, 6aa is formed in a highly regioselective manner, giving preferentially the ortho-isomer in a 15:1 ratio. A variety of terminal alkynes readily participated and provided arenes $\mathbf{6}$ in good yields and regioselectivities. For instance, ethynyl cyclopropane delivered aryl cyclopropane 6ac in high regioselectivity. 3-Chloro prop-1-yne reacted smoothly to give $\mathbf{6 a b}$, albeit with reduced regioselectivity. A range of aryl acetylenes were found to be competent substrates providing ortho-triazenyl biphenyls in good yields and regioselectivities. Variations of the steric and electronic parameters of the aryl groups, including a potentially catalyst poisoning 2-thioanisyl unit, had little impact on yields and regio-control of the cyclot-

rimerization (6ae-6ai). Heteroaryl alkynes also underwent cyclization. 3-Ethynyl thiophene gave product $\mathbf{6 a j}$ in good yield and the typical regioselectivity of 7:1. The related 3-ethynyl ( $N$ methyl)indole delivered arene 6ak with a lower selectivity. Surprisingly, two alkynes - TMS-1,3-diyne and methyl propiolate - caused a reversal of the regioselectivity. In these two cases, meta-substituted aryl triazene 6al and 6am were majorly formed. Concerning internal alkynes, diphenyl diacetylene reacted highly regioselectively and gave $\mathbf{6 a n}$. The combination of 4a with triazene 2a gave unique bis-triazenyl arene 6ao. A diyne with an oxygen tether and a phenyl group at $\mathrm{R}^{1}$ was also tolerated and provided para-triazenyl biphenyl $\mathbf{6 b j}$.

Scheme 3: [2 + 2 + 2] Cyclotrimerizations with 1-Diynyl Triazenes. $^{\text {a }}$

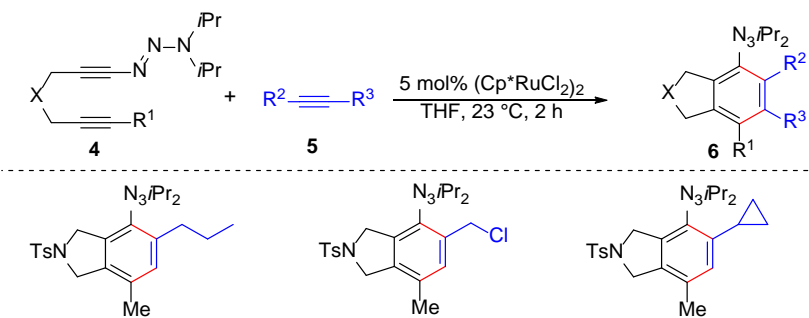

6aa ${ }^{(93 \%, 15: 1 \text { rs })}$

$\mathbf{6 a b}^{(81 \%, 3: 1 \mathrm{rs})}$

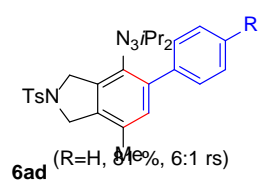

6ae (R=OMe, $86 \%, 6: 1 \mathrm{rs})$
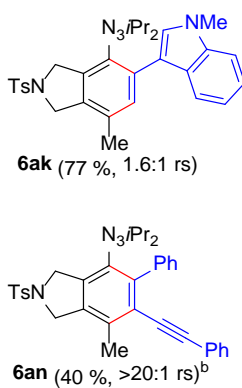

6af $\left(\mathrm{R}=\mathrm{CO}_{2} \mathrm{Me}, 71 \%, 5: 1 \mathrm{rs}\right)$

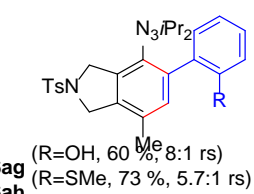
$\left.{ }_{6 \mathbf{6 a i}}{ }_{(\mathrm{R}=\mathrm{CO}}{ }_{2} \mathrm{Me}, 80 \%, 7.5: 1 \mathrm{rs}\right)$
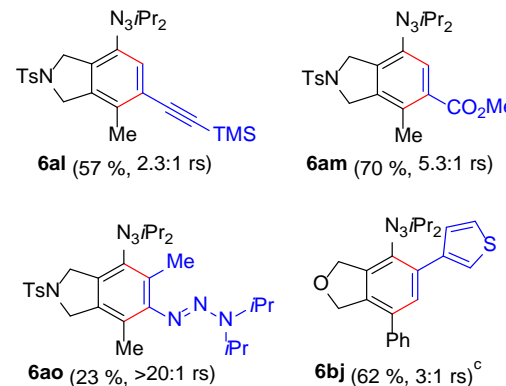

a Conditions: $0.1 \mathrm{mmol}$ 4, $0.15 \mathrm{mmol}$ 5, $5 \mathrm{~mol} \%\left(\mathrm{Cp} * \mathrm{RuCl}_{2}\right)_{2}$, $0.1 \mathrm{M}$ in THF, isolated yields, ratio of regioisomers determined by ${ }^{1} \mathrm{H}-\mathrm{NMR} .{ }^{\mathrm{b}} 60{ }^{\circ} \mathrm{C}, 20$ h. ${ }^{\mathrm{c}} 80^{\circ} \mathrm{C}, 4 \mathrm{~h}$.

Despite being an efficient strategy to access substituted fused pyridines, the scope of the cyclotrimerization between two alkynes and one nitrile is less broad compared to the parent reaction. In this aspect, reports on cyclizations involving tethered alkynyl nitriles are limited to nickel(0), ${ }^{21 \mathrm{a}}$ iron(II) ${ }^{21 \mathrm{~b}}$ and cobalt(I $)^{21 c-g}$ based systems, and they are largely met with regioselectivity issues. To explore this underdeveloped area, we investigated the feasibility of pyridine cyclization with alkynyl triazene $\mathbf{2 a}$ and tethered nitrile $\mathbf{7 a}$ (Table 2). The envisioned cyclization proceeded with very poor efficiency with the previously used $\left(\mathrm{Cp}^{*} \mathrm{RuCl}_{2}\right)_{2}$ (Entry 1 ). We switched to the cationic $\mathrm{Cp} * \mathrm{Ru}(\mathrm{MeCN})_{3} \mathrm{PF}_{6}$ complex in combination with halide additives (Entries 2-5). No reactivity was observed in the absence of additives, while switching the counter ion to iodide substantially improved the reactivity, presumably by a better coordination involvement of the nitrile group of $7 \mathbf{a}$. Notably only pyridine 8aa without traces of the isomer 8aa' was formed in $43 \%$ 
yield. Besides the desired pyridine, $28 \%$ of homocyclization product $\mathbf{z}$ was observed. Switching the solvent from THF to dioxane and increasing the temperature to $100{ }^{\circ} \mathrm{C}$ reduced this byproduct slightly while increasing the yield of pyridine 8aa to 71 $\%$ (Entry 8).

Table 2: Optimization of the Ru-Catalyzed Synthesis of Pyridyl Triazenes. $^{\mathrm{a}}$

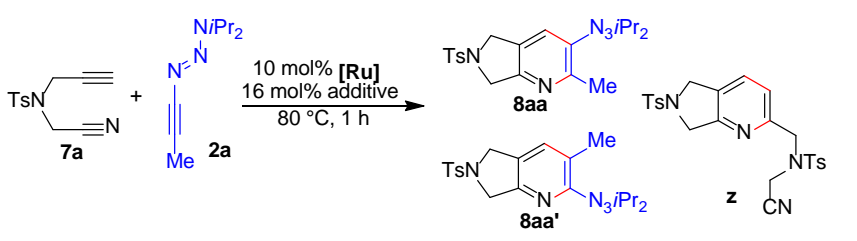

\begin{tabular}{|c|c|c|c|c|c|}
\hline Entry & {$[\mathrm{Ru}]$} & Additive & Solvent & $\% 8 \mathbf{a a}^{\mathrm{b}}$ & $\% \mathbf{z}^{\mathrm{b}}$ \\
\hline 1 & $\left(\mathrm{Cp} * \mathrm{RuCl}_{2}\right)_{2}$ & - & THF & 8 & 8 \\
\hline 2 & $\mathrm{Cp} * \mathrm{Ru}(\mathrm{MeCN})_{3} \mathrm{PF}_{6}$ & - & THF & - & $<5$ \\
\hline 3 & $\mathrm{Cp} * \mathrm{Ru}(\mathrm{MeCN})_{3} \mathrm{PF}_{6}$ & $\mathrm{Bu}_{4} \mathrm{NCl}$ & THF & 6 & 9 \\
\hline 4 & $\mathrm{Cp} * \mathrm{Ru}(\mathrm{MeCN})_{3} \mathrm{PF}_{6}$ & $\mathrm{Bu}_{4} \mathrm{NBr}$ & THF & 11 & 16 \\
\hline 5 & $\mathrm{Cp} * \mathrm{Ru}(\mathrm{MeCN})_{3} \mathrm{PF}_{6}$ & $\mathrm{Bu}_{4} \mathrm{NI}$ & THF & 43 & 28 \\
\hline 6 & $\mathrm{Cp} * \mathrm{Ru}(\mathrm{MeCN})_{3} \mathrm{PF}_{6}$ & $\mathrm{Bu}_{4} \mathrm{NI}$ & Dioxane & 53 & 30 \\
\hline 7 & $\mathrm{Cp} * \mathrm{Ru}(\mathrm{MeCN})_{3} \mathrm{PF}_{6}$ & $\mathrm{Bu}_{4} \mathrm{NI}$ & $\mathrm{MeCN}$ & $<5$ & $<5$ \\
\hline 8 & $\mathrm{Cp} * \mathrm{Ru}(\mathrm{MeCN})_{3} \mathrm{PF}_{6}$ & $\mathrm{Bu}_{4} \mathrm{NI}$ & Dioxane & $71^{\mathrm{c}, \mathrm{d}}$ & 21 \\
\hline
\end{tabular}

a Conditions: $0.15 \mathrm{mmol}$ 7a, $0.1 \mathrm{mmol}$ 2a, $10 \mathrm{~mol} \%$ [Ru], $0.1 \mathrm{M}$ in solvent. ${ }^{\mathrm{b}}$ Determined by ${ }^{1} \mathrm{H}-\mathrm{NMR}$ with an internal standard, 8aa:8aa' > 20:1. ${ }^{\text {c }}$ At $100{ }^{\circ} \mathrm{C}$. ${ }^{\mathrm{d}}$ Isolated yield.

The optimized conditions were subsequently utilized to prepare a small set of bicyclic pyridines (Scheme 4). Besides the classical malonate tether (8ba), we were pleased that the method is as well useful to access fused nitrogen- and oxygen containing six-membered fused pyridines such as 8ca and 8da. Alkynyl triazene $\mathbf{2}$ with longer alkyl chains engaged as well in the heterotrimerization and yielded pyridines 8cc and 8cf. In all cases, the pyridines are remarkably formed as single regio-isomers possessing their triazenyl group in the meta-position.

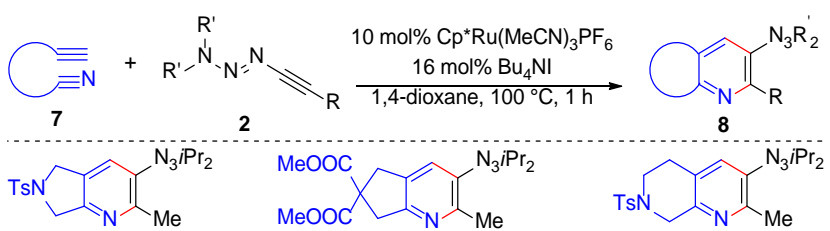

$8 \mathbf{a a}(71 \%,>20: 1$ rs)

8 ba $(61 \%,>20: 1$ rs)

8 ca $(95 \%,>20: 1$ rs $)$

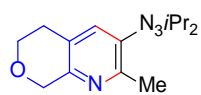

8da $(54 \%,>20: 1$ rs)b

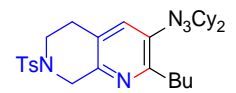

$8 \mathrm{cc}(60 \%,>20: 1 \mathrm{rs})$

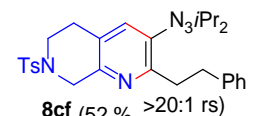

a Conditions: 0.1 mmol 2, 0.15 mmol 7, $10 \mathrm{~mol} \%$ $\mathrm{Cp} * \mathrm{Ru}(\mathrm{MeCN})_{3} \mathrm{PF}_{6}, 16 \mathrm{~mol}_{0}\left(\mathrm{Bu}_{4} \mathrm{~N}\right) \mathrm{I}, 0.1 \mathrm{M}$ in 1,4-dioxane, isolated yields. ${ }^{b}$ with $20 \mathrm{~mol} \% \mathrm{Cp} * \mathrm{Ru}(\mathrm{MeCN})_{3} \mathrm{PF}_{6}, 32 \mathrm{~mol} \%$ $(\mathrm{Bu} 4 \mathrm{~N}) \mathrm{I}$.

Next, we aimed to broaden the application potential further by permutation of the nitrogen atom's position in the arising pyridine products. To realize this goal, triazenyl diyne 4 was combined with a variety of nitriles with synthetically valuable functional groups (Scheme 5). ${ }^{22}$ The standard catalyst $\left[\mathrm{Cp} * \mathrm{RuCl}_{2}\right]_{2}$ was found to cleanly catalyze the reaction between 4a and malonitrile, selectively forming pyridine 10aa in $80 \%$ yield. The transformation is characterized by a good regioselectivity of 8.3:1 placing the triazenyl moiety meta to the pyridine nitrogen atom. Notably, no second [2+2+2] with the remaining nitrile group of 10aa was observed. Additionally, nitriles bearing attractive functionalities such as fumaronitrile, chloroand bromoacetonitrile as well as chloroacrylonitrile provided the desired pyridine products 10ab-10ae in good yields and regioselectivities. Mander's reagent reacted to give methylester substituted pyridine 10af. Nitriles bearing electron-withdrawing groups like benzoyl cyanide, $p$-nitro benzonitrile and 1,4dicyano benzene were also found to be competent reaction partners, giving 2-acylated, 2-arylated pyridines respectively. 2Phenyl pyridine 10ba was also generated from phenyl substituted diyne $\mathbf{4 b}$.
Scheme 4: Synthesis of 3-Triazenyl Pyridines with Tethered Nitriles. ${ }^{a}$
Scheme 5: Scope for the Synthesis of Pyridyl Triazenes from Nitriles $^{\text {a }}$ 


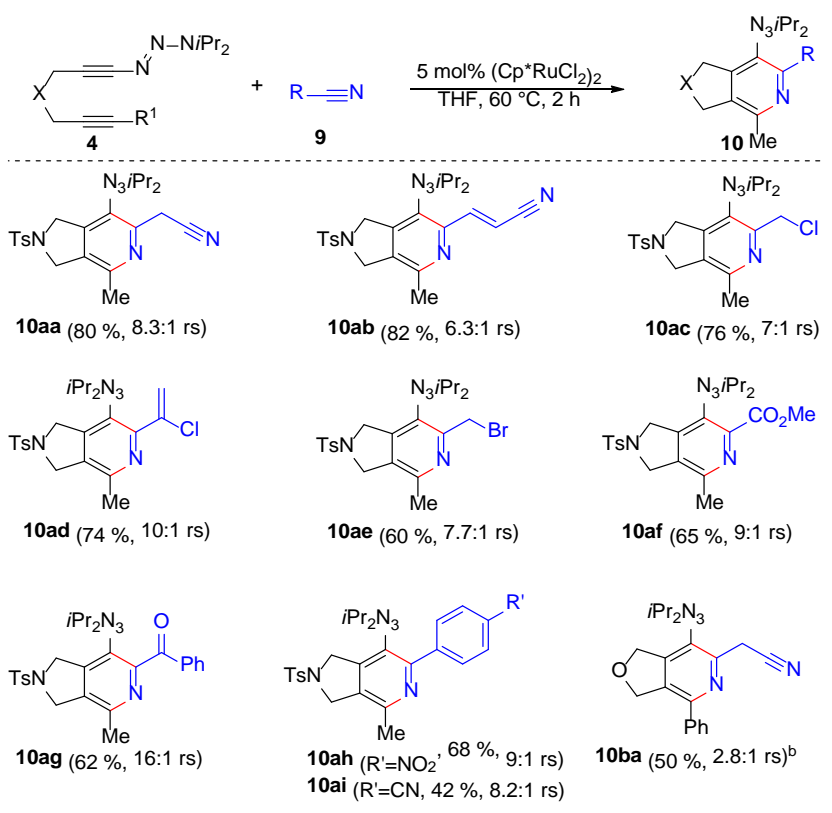

${ }^{a}$ Conditions: $0.1 \mathrm{mmol}$ 4, $0.15 \mathrm{mmol}$ 9, $5 \mathrm{~mol} \%\left(\mathrm{Cp} * \mathrm{RuCl}_{2}\right)_{2}$, $0.1 \mathrm{M}$ in THF; isolated yields, regioisomeric ratio determined by ${ }^{1} \mathrm{H}-\mathrm{NMR}$. ${ }^{\mathrm{b}} 10 \mathrm{~mol} \%\left(\mathrm{Cp} \mathrm{RuCl}_{2}\right)_{2}, 80^{\circ} \mathrm{C}, 4 \mathrm{~h}$.

\section{Elaboration of the triazenyl group}

Aryl triazenes are a highly versatile group that can be converted into a wide-ranging array of synthetically highly relevant functional groups. ${ }^{9-11}$ However, much less is known regarding the reactivity profile of pyridyl triazenes. Therefore, we opted for pyridine 8aa as a representative case for a basic and coordinating heterocycle and embarked to map its reactivity profile (Scheme 6). Many functionalizations operate under acidic conditions via protonation of the triazenyl group forming a diazonium intermediate. The presence of the basic pyridine nitrogen usually renders the reaction more delicate. We concluded that if they are successful with $\mathbf{8 a a}$, it is fair to assume a very high chance of success with less challenging substrates. Replacing the triazenyl groups by halides was realized by the treatment of 8aa with trimethylsilyl iodide to provide iodo pyridine $\mathbf{1 1} .^{9 \mathrm{~g}}$ Highly valuable 3-fluoro pyridine 12a was cleanly formed by exposure of 8aa to HF• pyridine..$^{9 i}$ Moreover, transformation of the triazenyl group into an azide functionality proceeded well with a soluble azide source under acidic conditions. ${ }^{10 c}$ The obtained pyridyl azide $\mathbf{1 3}$ can be further converted to triazole $\mathbf{1 4}$ by $\mathrm{Cu}$-catalyzed click reaction. Oxygen nucleophiles can be introduced by protonating the triazenyl group with TFA in the presence of an alcohol, e.g. 3-methoxypyridine 15. In analogy, the introduction of nitrogen nucleophiles is feasible via the Ritter reaction. For instance, protonation in acetonitrile as the solvent gave rise to 3-acetamido pyridine 16. Replacing the solvent by an aromatic hydrocarbon such as $p$-xylene allowed for a Friedel-Crafts reaction to give phenyl pyridine 17. Complementary aromatic triazenes can take over the role of the electrophilic partner for palladium-catalyzed cross-coupling reactions. ${ }^{11}$ In this respect, a Heck-reaction with 4-methyl styrene using triflic acid as additive delivered styryl pyridine $\mathbf{1 8}$ in good yield. Besides transformations involving a complete loss of all triazenyl nitrogen atoms, the intermediate pyridyl diazonium species can be utilized. For instance, Sc(OTf) $)_{3}$-catalyzed azo coupling with a beta-ketoester gave azo product 19 in $82 \%$ yield. ${ }^{10 a}$

\section{Scheme 6: Synthetic Transformations of Pyridyl Triazene 8aa}

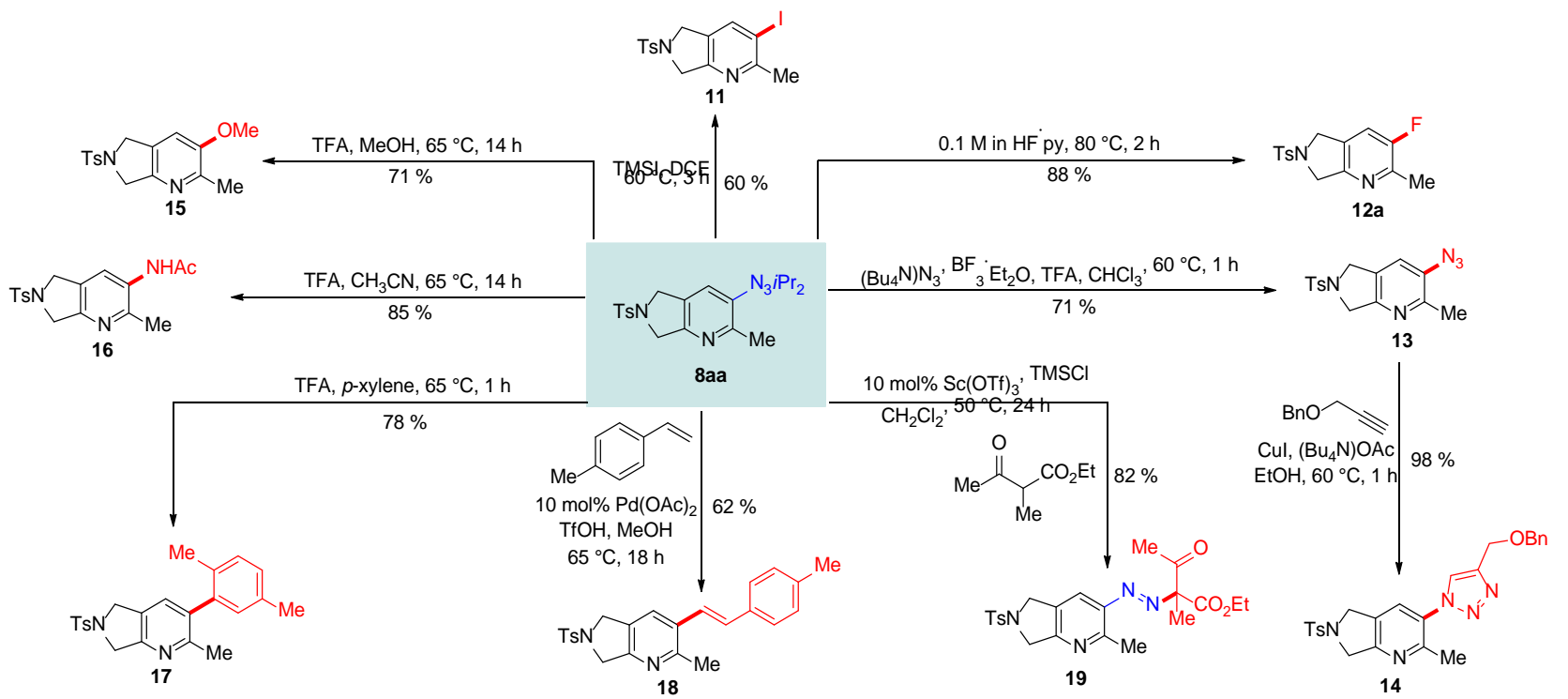


In order to gauge the generality and robustness of the product derivatizations, selected members from different product categories were treated with HF•pyridine under the aforementioned conditions (Scheme 7). All triazenyl groups were efficiently converted to the corresponding aryl fluorides 12b-12e in 70-96 $\%$ yield.

Scheme 7: Exemplary Fluorinations of Aryl and Pyridyl Triazenes.

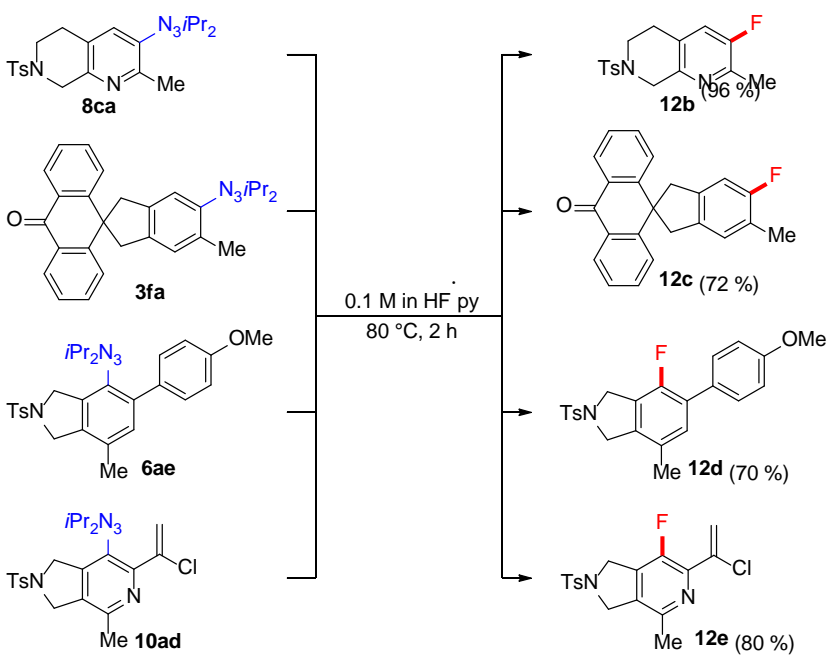

In addition to transformations of the triazenyl group with external nucleophiles, appropriate ortho-substituents allow for rich cyclization chemistry and provide rapid access to synthetically useful heterocycles (Scheme 8) ${ }^{4,5}$. For examples, ortho-alkynyl triazene 3ma was converted into bromo cinnoline 20 by exposure to aqueous $\mathrm{HBr}{ }^{5 \mathrm{i}} \mathrm{A}$ smooth ring closure to dibenzofuran 21 was achieved from phenol $\mathbf{6 a g} .{ }^{5 \mathrm{k}}$ In close analogy, thioanisole 6ah formed dibenzothiophene 22 under acidic conditions. ${ }^{5 e}$

Scheme 8: Use of the Triazene Handle for the Formation of Heterocycles.
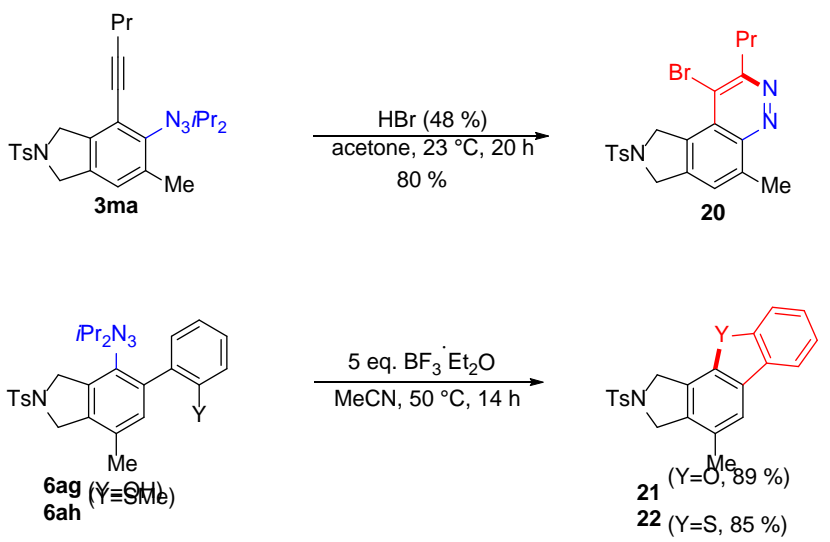

\section{Coordination chemistry of alkynyl triazenes}

The cyclotrimerization reactions described above require a coordination of the alkynyl triazene to the $\mathrm{Cp} * \mathrm{Ru}$ fragment at some stage during the catalytic cycle. So far, the coordination chemistry of alkynyl triazenes is completely unexplored, and it was not clear if binding to a late transition-metal complex such as $\mathrm{Cp} * \mathrm{RuCl}$ would occur via its triple bond or via its triazene group. In order to gain further insight, we studied reactions of the tetramer $(\mathrm{Cp} * \mathrm{RuCl})_{4}$, a common precursor for the $\mathrm{Cp} * \mathrm{RuCl}$ fragment, with alkynyl triazenes. First investigations were performed with alkynyl triazene $\mathbf{2 g}$ (Scheme 9). We expected that the bulky tert-butyl group next to the triple bond would favor the coordination of the triazene function. However, when the reaction mixture was analyzed by ${ }^{13} \mathrm{C}$ NMR spectroscopy $\left(\mathrm{CD}_{2} \mathrm{Cl}_{2}\right)$, the data indicated the formation of a $\eta^{2}$-bound alkyne complex (23). Characteristic deshielded signals were observed for alkyne $\mathrm{C}$ atoms, which appeared at 143.4 and $154.6 \mathrm{ppm}$, respectively. For comparison, the corresponding $\mathrm{C}_{\mathrm{sp}}$ resonances for alkyne $2 \mathbf{g}$ are found at 84.3 and $88.5 \mathrm{ppm}\left(\mathrm{CDCl}_{3}\right) .{ }^{14}$ The strong deshielding of the ${ }^{13} \mathrm{C}$ NMR signals suggested that that the alkyne acts as a four electron donor in this complex. ${ }^{26}$

Complexes of the formula (cyclopentadienyl) $\operatorname{RuCl}\left(\eta^{2}\right.$-alkyne) are notoriously difficult to isolate. ${ }^{27}$ Common problems are facile decomplexation of the weakly bound alkyne ligand, and follow-up reaction such as [2 +2$]$ cycloadditions. Both types of problems were encountered during our investigations, and we were not able to synthesize the adduct $\mathbf{2 3}$ on a preparative scale in pure form. However, we did manage to obtain single crystals of complex $\mathbf{2 3}$ by storing a saturated solution of the complex in diethyl ether at $-20^{\circ} \mathrm{C}$.

\section{Scheme 9. Reaction of $\left(\mathrm{Cp}^{*} \mathrm{RuCl}\right)_{4}$ with Alkynyl Triazene} 2g.

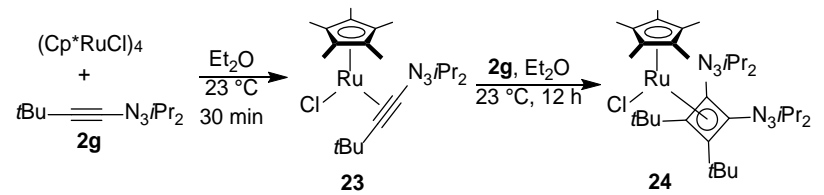

The molecular structure of complex 23 was determined by $\mathrm{X}$-ray diffraction, and a graphic representation is shown in Figure 2a. ${ }^{28}$ As already indicated by the NMR data, the alkynyl triazene is bound via the triple bond to the $\mathrm{Cp} * \mathrm{RuCl}$ fragment. The coordination to the $\mathrm{Ru}$ leads to an elongation of the triple bond: for complex 23, a C1-C2 distance of 1.274(5) $\AA$ is observed, where as a value of $1.2033(14) \AA$ is found for $t$ BuCCN $\mathrm{Me}_{2}$, a close analogue of $\mathbf{2 g} .{ }^{14}$ Furthermore, one can observe a strong bending away from linearity, with a C1-C2-C3 angle of only $141.3^{\circ}$. 

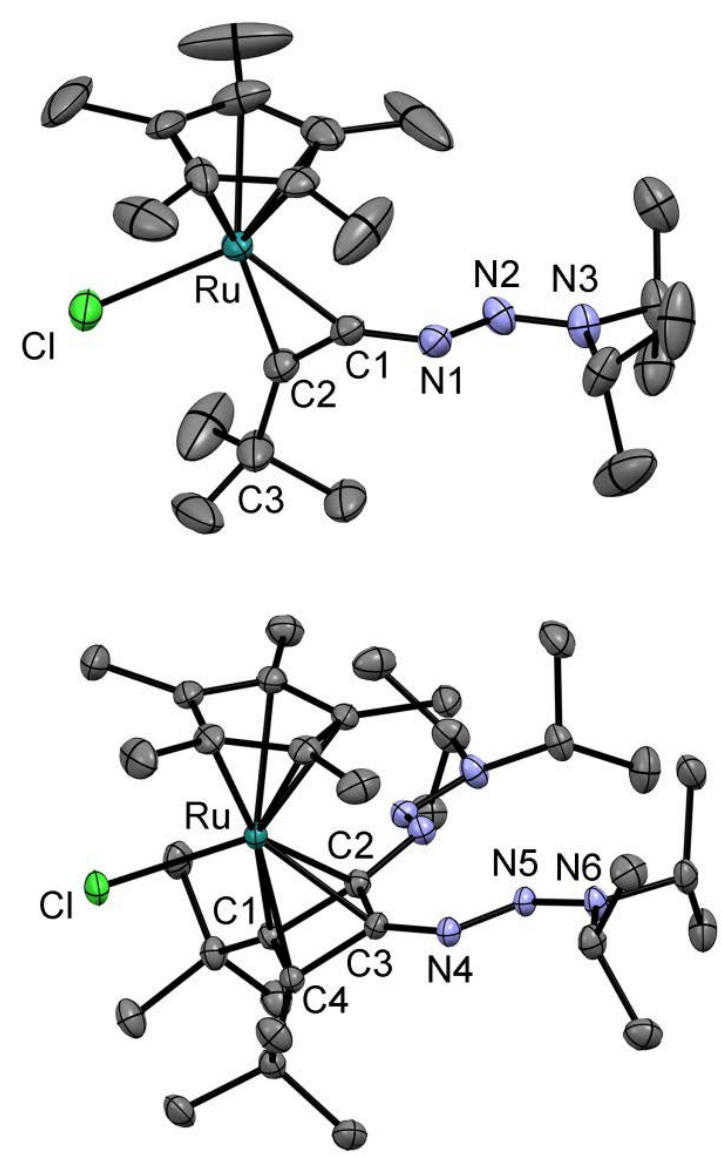

Figure 2. Molecular structures of complex 23 (a) and 24 (b) in the crystal. Hydrogen atoms are omitted for clarity. The ellipsoids are at $50 \%$ probability. Selected bond lengths $(\AA \AA)$ and angles $\left({ }^{\circ}\right)$ : 23: Ru-Cl 2.413(2), Ru-C1 2.040(5), Ru-C2 2.061(3), C1-C2 1.274(5), C1-N1 1.382(6), N1-N2 1.276(17), N2-N3 1.342(9), C1-C2-C3 141.3, C2-C1-N1 147.4; 25: Ru-Cl 2.4217(5), Ru-C1 2.1698(17), Ru-C2 2.1978(17), Ru-C3 2.1792(17), Ru-C4 .21450(17), C3-N4 1.392(2), N4-N5 1.279(2), N5-N6 1.325(2).

The reaction between $(\mathrm{Cp} * \mathrm{RuCl})_{4}$ and an excess of alkyne $\mathbf{2 g}$ resulted in the formation of the cyclobutadiene complex 24, which was isolated in $71 \%$ yield (Scheme 9). A crystallographic analysis ${ }^{25}$ revealed that the alkynyl triazene had undergone a head-to-head dimerization, as it is often observed for Cp*RuCl(cyclobutadiene) complexes. ${ }^{27 \mathrm{~b}, 29}$ The $\mathrm{Ru}-\mathrm{Cl}$ bond distance (2.413(2) $\AA$ ), as well as the distances between the carbon atoms of the cyclobutadiene ring and the $\mathrm{Ru}$ center $\left(\mathrm{Ru}-\mathrm{C}_{\mathrm{av}}\right.$. $2.17 \AA$ ) are within the expected range. The planes defined by the triazene groups are nearly coplanar with the plane defined by the cyclobutadiene ring. This structural feature suggests that there is electronic communication between the triazene groups and the four-membered ring. Changing the substituent on the alkynyl triazene from tert-butyl to a less bulky n-butyl group had a pronounced effect of the outcome of the reaction. When $(\mathrm{Cp} * \mathrm{RuCl})_{4}$ was mixed with triazene $\mathbf{2 h}$, we were not able to detect a simple adduct of type $\mathrm{Cp}^{*} \mathrm{RuCl}(\mathbf{2 h})$. Instead, dinuclear complex 25 was found (Scheme 10).

Scheme 10. Reaction of $(\mathrm{Cp} * \mathrm{RuCl})_{4}$ with Alkynyl Triazene 2h.

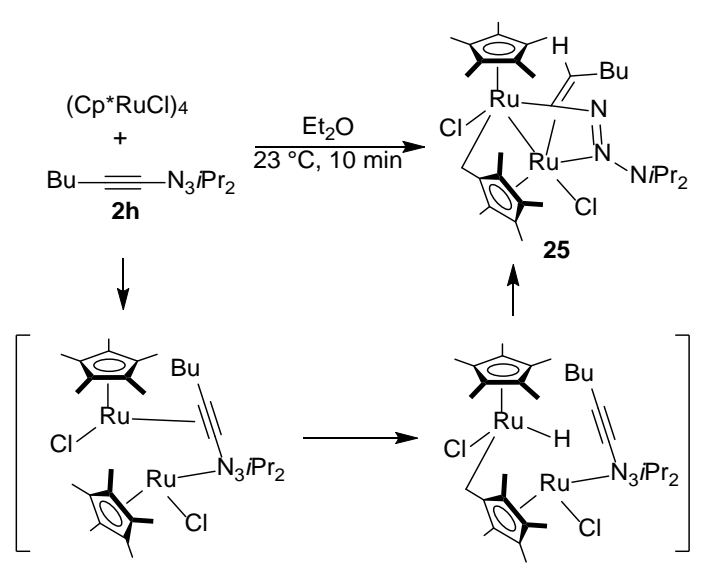

The solid state structure of complex 25 is depicted in Figure $3 .^{28}$ A peculiar feature of $\mathbf{2 5}$ is the presence of a bridging, $\eta^{1}: \eta^{5}$-bound tetramethylfulvene ligand. ${ }^{30}$ Furthermore, one can observe a metalated vinyl triazene ligand. The latter also acts as a bridging ligand, with coordination to the $\mathrm{Cp} * \mathrm{RuCl}$ centers via the vinyl group and the central N3 atom of the triazene function. A plausible mechanism for the formation of $\mathbf{2 5}$ involves coordination of two $\mathrm{Cp} * \mathrm{RuCl}$ fragments to one alkynyl triazene (Scheme 10). The simultaneous complexation to the same alkyne promotes an oxidative addition of the $\mathrm{Cp}^{*}$ methyl group, resulting in the formation of a hydride complex. Insertion of the triple bond into to the $\mathrm{Ru}-\mathrm{H}$ bond then gives complex 25. It should be noted that complex $\mathbf{2 5}$ was only isolated in modest yield, and we were not able to identify other reaction products. Although an X-ray crystal structure of $\mathbf{2 5}$ was obtained, isolation of pure $\mathbf{2 5}$ on a preparative scale failed due to its lability in solution. Still, the formation of complex $\mathbf{2 5}$ is evidence that the organometallic chemistry of alkynyl triazenes can be quite distinct from the one of 'normal' alkynes.

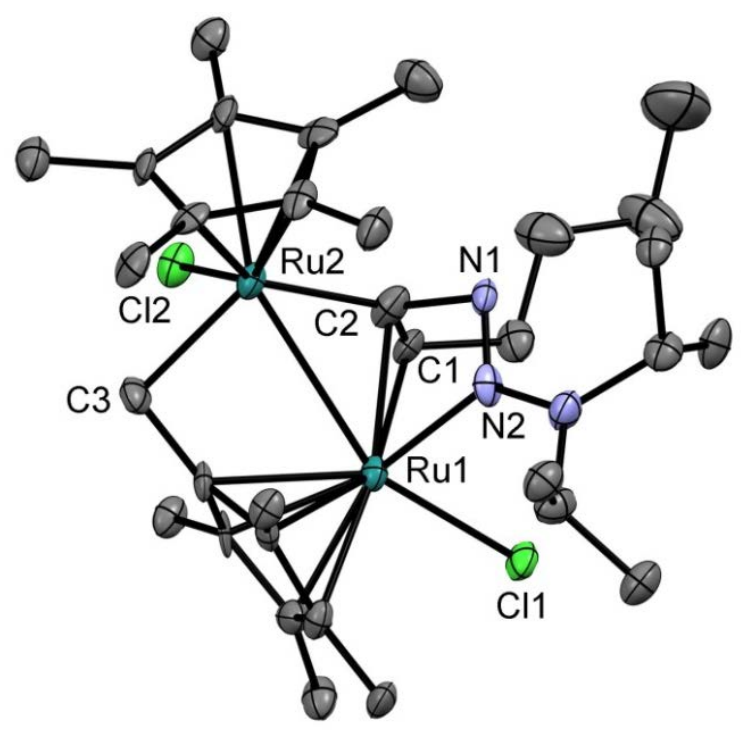


Figure 3. Molecular structure of complex 25 in the crystal. Hydrogen atoms and solvent molecules are omitted for clarity. The ellipsoids are at $50 \%$ probability. Selected bond lengths $(\AA \AA)$ and angles ( ${ }^{\circ}$ : Ru1-Cl1 2.407(2), Ru1-N2 2.144(8), Ru1-C1 2.356(11), Ru1C2 2.211(11), Ru2-Cl2 2.455(3), Ru2-C3 2.134(10), Ru2-C2 2.044(11), Ru1-Ru2 3.0094(11).

\section{Investigation of potential catalyst deactivation pathways}

The rapid formation of ruthenium complexes 24 and 25 with alkynyl triazenes raises the question of their bearing on the cyclotrimerization catalysis. In this respect, a set of control experiments using ruthenium complex $\mathbf{2 4}$ was conducted (Scheme 11). Exposure of 1a and 2a towards complex 24 did not yield any cyclotrimerization product. In comparison, both $\left[\mathrm{Cp} * \mathrm{RuCl}_{2}\right]_{2}$ and $[\mathrm{Cp} * \mathrm{RuCl}]_{4}$ efficiently catalyze the formation of 3aa. This outcome was confirmed by the attempted reaction between alkynyl triazene $\mathbf{4 a}$ and alkyne $\mathbf{5 j}$. $\left[\mathrm{Cp} * \mathrm{RuCl}_{2}\right]_{2}$ and $[\mathrm{Cp} * \mathrm{RuCl}]_{4}$ reliably provided arene 6aj in comparable yields and regioselectivity, whereas complex $\mathbf{2 4}$ was catalytically inactive. In a last simplified control, diyne 1a without any additional alkyne was exposed to the different ruthenium complexes. As expected $[\mathrm{Cp} * \mathrm{RuCl}]_{4}$ formed double $[2+2+2]$ trimer $\mathbf{y}$ in almost quantitative yield. Exposure of $\mathbf{1 a}$ to complex $\mathbf{2 4}$ gave moderate yields of dimerization product $\mathbf{x}$ and a small amount of trimer $\mathbf{y}$. It indicates that the cyclobutadiene ligand of $\mathbf{2 4}$ can dissociate over time. To some degree, $\mathbf{2 4}$ is capable of reentering a productive catalytic cycle.

Scheme 11: Assessment of the Catalytic Competence of Ruthenium Complex 24. a)

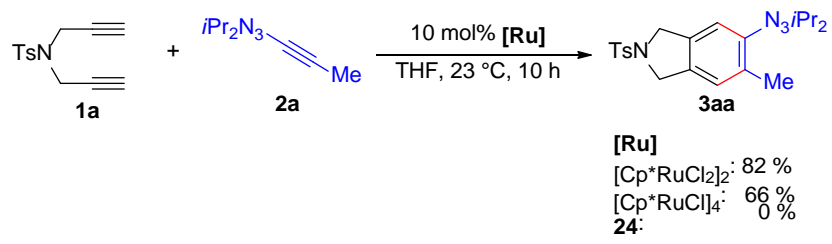

b)
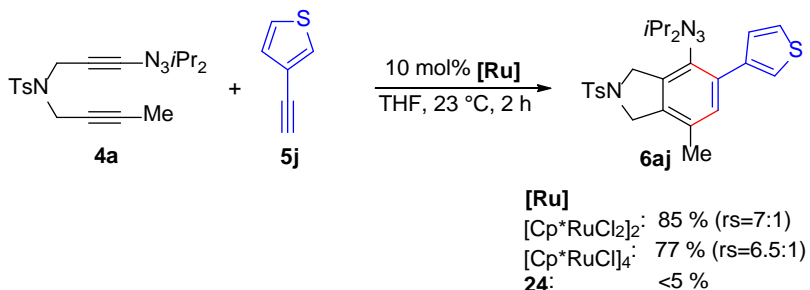

c)
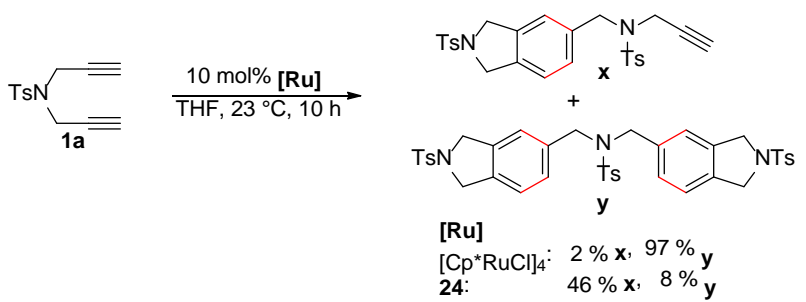

Due to difficulties to prepare complex $\mathbf{2 5}$ on a preparative scale, we have not performed control experiments with this complex. Nevertheless, it is conceivable that dimeric complexes of this type are involved in catalyst deactivation. If this was the case, prevention of the initial steps of the deactivation pathway, namely the putative $\mathrm{C}-\mathrm{H}$ activation of the methyl group of the Cp* ligand, may allow for improved methods with lower catalyst loadings.

\section{Conclusion}

In summary, we have reported the cyclotrimerization of 1alkynyl triazenes for the convenient access to densely functionalized aryl and pyridyl triazenes. These findings significantly expand the synthetic utility of alkynyl triazenes and highlight their compatibility with transition metal catalysts, especially ruthenium. The Cp*Ru-catalyzed [2 + 2+2] cyclotrimerization proceeds well both with simple alkynyl triazenes and tethered 1-diynyl triazenes. Attractively, the methods could be extended to pyridine synthesis by replacing an alkyne with a nitrile. Generally, the reactions are characterized by a very pronounced regioselectivity induced by the triazenyl group and notably yield the sterically more hindered product. The precisely installed triazene group of the formed aromatic ring is a highly versatile moiety which is smoothly converted into the most important functional aryl substituents, including fluorides. This makes the method extremely useful for divergent functionality manipulations on these bicyclic motifs. Moreover, such triazenes engage equally well in intramolecular transformation to afford a variety of valuable heterocycles. Investigations of the largely unknown coordination chemistry of alkynyl triazenes revealed not only a rare $\mathrm{Cp} * \mathrm{RuCl}\left(\eta^{2}\right.$-alkyne) complex, but as well unusual addi- 
tional complexes. These species may be linked to catalyst deactivation and can provide some guidance to design even better performing catalysts.

\section{ASSOCIATED CONTENT}

\section{Supporting Information}

Synthetic procedures, characterization data for all new compounds. This material is available free of charge via the Internet at http://pubs.acs.org.

\section{AUTHOR INFORMATION}

\section{Corresponding Authors}

* nicolai.cramer@epfl.ch

*kay.severin@epfl.ch

\section{Notes}

The authors declare no competing financial interests.

\section{ACKNOWLEDGMENT}

This work is supported by the EPFL and the Swiss National Science Foundation (No 200021_157085). We thank Dr. R. Scopelliti and Dr. F. Fadaei Tirani for X-ray crystal structure analyses.

\section{REFERENCES}

(1) For reviews, see: (a) Kölmel, D. K.; Jung, N.; Bräse, S. Azides Diazonium Ions - Triazenes: Versatile Nitrogen-rich Functional Groups Aust. J. Chem. 2014, 67, 328-336. (b) Bräse, S. The virtue of the multifunctional triazene linkers in the efficient solid-phase synthesis of heterocycle lifluoridesries. Acc. Chem. Res. 2004, 37, 805-816. (c) Kimball, D. B.; Haley, M. M. Triazenes: a versatile tool in organic synthesis. Angew. Chem., Int. Ed. 2002, 41, 3338-3498.

(2) (a) Vajs, J.; Steiner, I.; Brozovic, A.; Pevec, A.; Ambriović-Ristov, A.; Matković, M.; Piantanida, I.; Urankar, D.; Osmak, M.; Košmrlj, J. The 1,3diaryltriazenido(p-cymene)ruthenium(II) complexes with a high in vitro anticancer activity. J. Inorg. Biochem. 2015, 153, 42-48. (b) Marchesi, F.; Turriziani, M.; Tortorelli, G.; Avvisati, G.; Torino, F.; De Vecchis, L. Triazene compounds: Mechanism of action and related DNA repair systems. Pharmacol. Res. 2007, 56, 275-287. (c) Serrone, L.; Zeuli M.; Sega, F. M.; Cognetti, F. Dacarbazine-based chemotherapy for metastatic melanoma: thirty-year experience overview. J. Exp. Clin. Cancer Res. 2000, 19, 21-34. (d) Newlands, E. S.; Stevens, M. F. G.; Wedge, S. R.; Wheelhouse, R. T.; Brock, C. Temozolomide: a review of its discovery, chemical properties, preclinical development and clinical trials. Cancer Treat. Rev. 1997, 23, 35-61. (e) Hickman, J. A. Investigation of the mechanism of action of antitumour dimethyltriazenes. Biochimie 1978, 60, 997-1002.

(3) (a) Torres-García, C.; Pulido, D.; Albericio, F.; Royo, M.; Nicolás, E. Triazene as a Powerful Tool for Solid-Phase Derivatization of Phenylalanine Containing Peptides: Zygosporamide Analogues as a Proof of Concept. J. Org. Chem. 2014, 79, 11409-11415. (b) Nicolaou, K. C.; Boddy, C. N. C. Atropselective Macrocyclization of Diaryl Ether Ring Systems: Application to the Synthesis of Vancomycin Model Systems. J. Am. Chem. Soc. 2002, 124 10451-10455. (c) Nicolaou, K. C.; Boddy, C. N. C.; Li, H.; Koumbis, A. E.; Hughes, R.; Natarajan, S.; Jain, N. F.; Ramanjulu, J. M.; Bräse, S.; Solomon, M. E. Total Synthesis of Vancomycin-Part 2: Retrosynthetic Analysis, Synthesis of Amino Acid Building Blocks and Strategy Evaluations. Chem. Eur. J. 1999, 5, 2602-2621.

(4) For review, see: Dong, W.; Chen, Z.; Xu, J.; Miao, M.; Ren, H. Synthesis of Benzo-Fused Cyclic Compounds via Intramolecular Cyclization of Aryltriazenes. Synlett 2016, 27, 1318-1334.

(5) Intramolecular cyclizations with aromatic triazenes: (a) Xu, L.; Yang, W.; Zhang, L.; Miao, M.; Yang, Z.; Xu, X.; Ren, H. Brönsted Acid-Mediated Intramolecular Cyclization of Biaryl Triazenes for the Synthesis of Fluorenes and 9,10-Dihydro-Phenanthrenes. J. Org. Chem. 2014, 79, 9206-9221. (b) Fang, Y.; Wang, C.; Su, S.; Yu, H.; Huang, Y. Selective synthesis of indazoles and indoles via triazene-alkyne cyclization switched by different metals. Org.
Biomol. Chem. 2014, 12, 1061-1071. (c) Shang, X.; Xu, L.; Yang, W.; Zhou, J.; Miao, M.; Ren, H. BF $\cdot \mathrm{OEt}_{2}$-Promoted Intramolecular Nucleophilic Substitution; Synthesis of Dibenzopyranones and Coumarins from Biaryltriazenes. Eur. J. Org. Chem. 2013, 2013, 5475-5484. (d) Yang, W.; Yang, Z.; Xu, L.; Zhang, L.; Xu, X.; Miao, M.; Ren, H. Surfactant-Type Brønsted Acid Catalyzed Stereoselective Synthesis of trans-3-Alkenyl Indazoles from Triazenylaryl Allylic Alcohols in Water. Angew. Chem., Int. Ed. 2013, 52, 14135-14139. (e) Shang, X.; Chen, W.; Yao, Y. A Simple and Efficient Synthesis of Dibenzothiophene via $\mathrm{BF}_{3} \cdot \mathrm{OEt}_{2}$-Promoted Intramolecular Annulation. Synlett 2013, 24, 851-854. (f) Chen, Z.; Yang, W.; $\mathrm{Xu}$, L.; Zhang, L.; Miao, M.; Ren, H. $\mathrm{BF}_{3} \cdot \mathrm{OEt}_{2}$-Promoted Tandem OArylation/Hydroxylation: Efficient Synthesis of 2-Hydroxyflavanones from Triazenylaryl-Substituted Diketones. Eur. J. Org. Chem. 2013, 2013, 74117420. (g) Wang, C.; Sun, H.; Fang, Y.; Huang, Y. General and Efficient Synthesis of Indoles through Triazene-Directed C-H Annulation. Angew. Chem., Int. Ed. 2013, 52, 5795-5798. (h) Zhao, G.; Wang, B.; Yang, W.; Ren, H. Lewis-Acid-Promoted Arylation Reaction: Synthesis of Dihydrobenzofuran Derivatives from Aryltriazenes. Eur. J. Org. Chem. 2012, 2012, 6236-6247. (i) Zhou, J.; Yang, W.; Wang, B.; Ren, H. Friedel-Crafts Arylation for the Formation of C-C Bonds: A Route to Unsymmetrical and Functionalized Polycyclic Aromatic Hydrocarbons from Aryl Triazenes. Angew. Chem., Int. Ed. 2012, 51, 12293-12297. (j) Young, B. S.; Marshall, J. L.; MacDonald, E.; Vonnegut, C. L.; Haley, M. M. Diazaheterocycle analogues of tetracene: synthesis and properties of a naphtho-fused cinnoline and a naphtho-fused isoindazole. Chem. Commun. 2012, 48, 5166-5168. (k) Yang, W.; Zhou, J.; Wang, B.; Ren, H. Lewis Acid-Promoted Synthesis of Unsymmetrical and Highly Functionalized Carbazoles and Dibenzofurans from Biaryl Triazenes: Application for the Total Synthesis of Clausine C, Clausine R, and Clauraila A. Chem. - Eur. J. 2011, 17, 13665-13669. (l) Zhou, J.; He, J.; Wang, B.; Yang, W.; Ren, H. 1,7-Palladium Migration via C-H Activation, Followed by Intramolecular Amination: Regioselective Synthesis of Benzotriazoles. J. Am. Chem. Soc. 2011, 133, 6868-6870. (m) Kale, R. R.; Prasad, V.; Hussain, H. A.; Tiwari, V. K. Facile route for N1-aryl benzotriazoles from diazoamino arynes via CuI-mediated intramolecular Narylation. Tetrahedron Lett. 2010, 51, 5740-5743. (n) Liu, Q. L.; Wen, D. D.; Hang, C. C.; Li, Q. L.; Zhu, Y. M. A novel and regiospecific synthesis of 1aryl-1H-benzotriazoles via copper(I)-catalyzed intramolecular cyclization reaction. Helv. Chim. Acta 2010, 93, 1350-1354. (o) Goeminne, A.; Scammells, P. J.; Devine, S. M.; Flynn, B. L. Richter cyclization and cocyclization reactions of triazene-masked diazonium ions. Tetrahedron Lett. 2010, 51, 6882-6885. (p) Kimball, D. B.; Weakley, T. J. R.; Haley, M. M. Cyclization of 1-(2-Alkynylphenyl)-3,3-dialkyltriazenes: A Convenient, High-Yield Synthesis of Substituted Cinnolines and Isoindazoles. J. Org. Chem. 2002, 67, 6395-6405. (q) Wirschun, W.; Winkler, M.; Lutz, K.; C. Jochims, J. 1,3-Diaza-2-azoniaallene salts: cycloadditions to alkynes, carbodiimides and cyanamides. J. Chem. Soc., Perkin Trans. 1 1998, 11, 1755-1762.

(6) (a) Döbele, M.; Vanderheiden, S.; Jung, N.; Brase, S. Synthesis of Aryl Fluorides on a Solid Support and in Solution by Utilizing a Fluorinated Solvent. Angew. Chem., Int. Ed. 2010, 49, 5986-5988. (b) Gil, C.; Bräse, S. Solid-Phase Synthesis of Biologically Active Benzoannelated Nitrogen Heterocycles: An Update. J. Comb. Chem. 2009, 11, 175-197. (c) Dahmen, S.; Bräse, S. The First Stable Diazonium Ion on Solid Support-Investigations on Stability and Usage as Linker and Scavenger in Solid-Phase Organic Synthesis. Angew. Chem., Int. Ed. 2000, 39, 3681-3683. (d) Bräse, S.; Dahmen, S.; Pfefferkorn, M. Solid-Phase Synthesis of Urea and Amide Libraries Using the T2 Triazene Linker. J. Comb. Chem. 2000, 2, 710-715. (7) (a) Flatt, A. K.; Chen, B.; Tour, J. M. Fabrication of Carbon Nanotube-Molecule-Silicon Junctions. J. Am. Chem. Soc. 2005, 127, 89188919. (b) Delgado, J. L.; de la Cruz, P.; López-Arza, V.; Langa, F.; Kimball, D. B.; Haley, M. M.; Araki, Y.; Ito, O. The Isoindazole Nucleus as a Donor in Fullerene-Based Dyads. Evidence for Electron Transfer. J. Org. Chem. 2004, 69, 2661-2668. (c) Jones, L.; Schumm, J. S.; Tour, J. M. Rapid Solution and Solid Phase Syntheses of Oligo(1,4-phenylene ethynylene)s with Thioester Termini: Molecular Scale Wires with Alligator Clips. Derivation of Iterative Reaction Efficiencies on a Polymer Support. J. Org. Chem. 1997, 62, 1388-1410. (d) Moore, J. S. Shape-Persistent Molecular Architectures of Nanoscale Dimension. Acc. Chem. Res. 1997, 30, 402-413.

(8) For review, see: Zhang, Y.; Cao, D.; Liu, W.; Hu, H.; Zhang, X.; Liu, C. Recent Applications of Aryltriazenes in Organic Synthesis via C-N/N-N Bond Cleavage. Curr. Org. Chem. 2015, 19, 151-178.

(9) Halogenation of aromatic triazenes: (a) Pilot, C.; Dahmen, S.; Lauterwasser, F.; Bräse, S. Cleavage of immobilized disubstituted triazenes 
with electrophiles: solid-phase synthesis of alkyl halides and esters. Tetrahedron Lett. 2001, 42, 9179-9181. (b) Patrick, T. B.; Juehne, T.; Reeb, E.; Hennessy, D. Zinc(II) promoted conversion of aryltriazenes to aryl iodides and aryl nitriles. Tetrahedron Lett. 2001, 42, 3553-3554. (c) Barbero, M.; Degani, I.; Diulgheroff, N.; Dughera, S.; Fochi, R. 1-Aryl-3,3dialkyltriazenes: A Convenient Synthesis from Dry Arenediazonium oBenzenedisulfonimides - A High Yield Break Down to the Starting Dry Salts and Efficient Conversions to Aryl Iodides, Bromides and Chlorides. Synthesis 2001，2001，2180-2190. (d) Wu, Z.; Moore, J. S. Iodine-promoted decomposition of 1-aryl-3,3-dialkyltriazenes: A mild method for the synthesis of aryl iodides. Tetrahedron Lett. 1994, 35, 5539-5542. (e) Moore, J. S.; Weinstein, E. J.; Wu, Z. A convenient masking group for aryl iodides. Tetrahedron Lett. 1991, 32, 2465-2466. (f) Satyamurthy, N.; Barrio, J. R.; Schmidt, D. G.; Kammerer, C.; Bida, G. T.; Phelps, M. E. Acid-catalyzed thermal decomposition of 1-aryl-3,3-dialkyltriazenes in the presence of nucleophiles. J. Org. Chem. 1990, 55, 4560-4564. (g) Ku, H.; Barrio, J. R. Convenient synthesis of aryl halides from arylamines via treatment of 1-aryl-3,3dialkyltriazenes with trimethylsilyl halides. J. Org. Chem. 1981, 46, 52395241. (h) Foster, N. I.; Heindel, N. D.; Burns, H. D.; Muhr, W. Aryl Iodides from Anilines via Triazene Intermediates. Synthesis 1980, 1980, 572-573. (i) Rosenfeld, M. N.; Widdowson, D. A. A mild and efficient method of aromatic fluorination. J. Chem. Soc., Chem. Commun. 1979, 20, 914-916.

(10) Selected examples of triazene derivatizations: (a) Liu, C.; Lv, J.; Luo, S.; Cheng, J.-P. Sc(OTf)3-Catalyzed Transfer Diazenylation of 1,3-Dicarbonyls with Triazenes via N-N Bond Cleavage. Org. Lett. 2014, 16, 5458-5461. (b) Hafner, A.; Bräse, S. Trifluoromethylation of 1-Aryl-3,3diisopropyltriazenes. Adv. Synth. Catal. 2013, 355, 996-1000. (c) Liu, C.-Y.; Knochel, P. Preparation of Polyfunctional Aryl Azides from Aryl Triazenes. A New Synthesis of Ellipticine, 9-Methoxyellipticine, Isoellipticine, and $7-$ Carbethoxyisoellipticine. J. Org. Chem. 2007, 72, 7106-7115. (d) Knepper, K.; Vanderheiden, S.; Bräse, S. Nitrogen Functionalities in PalladiumCatalyzed Reactions on Solid Supports: A Case Study. Eur. J. Org. Chem. 2006, 2006, 1886-1898. (e) Bräse, S.; Enders, D.; Köbberling, J.; Avemaria, F. A Surprising Solid-Phase Effect: Development of a Recyclable "Traceless" Linker System for Reactions on Solid Support. Angew. Chem., Int. Ed. 1998, 37, 3413-3415. (f) Satyamurthy, N.; Barrio, J. R.; Bida, G. T.; Phelps, M. E. Efficient conversion of 1-aryl-3, 3-dialkyltriazenes to phenols and oxygen-18 labeled phenols. Tetrahedron Lett. 1990, 31, 4409-4412. (g) Lunn, G.; Sansone, E. B.; Keefer, L. K. General Cleavage of N-N and N-O Bonds Using Nickel/Aluminum Alloy. Synthesis 1985, 1985, 1104-1108.

(11) Cross coupling reactions using triazenes: (a) Dai, W.-C.; Wang, Z.-X. Palladium-catalyzed coupling of azoles with 1 -aryltriazenes via $\mathrm{C}-\mathrm{H} / \mathrm{C}-\mathrm{N}$ cleavage. Org. Chem. Front. 2017, 4, 1281-1288. (b) Saeki, T.; Son, E.-C.; Tamao, K. Boron Trifluoride Induced Palladium-Catalyzed Cross-Coupling Reaction of 1-Aryltriazenes with Areneboronic Acids. Org. Lett. 2004, 6, 617619. (c) Saeki, T.; Matsunaga, T.; Son, E.-C.; Tamao, K. Palladium-Catalyzed Cross-Coupling Reaction of 1-Aryltriazenes with Aryl- and Alkenyltrifluorosilanes. Adv. Synth. Catal. 2004, 346, 1689-1692. (d) Bräse, S.; Schroen, M. Efficient Cleavage-Cross-Coupling Strategy for Solid-Phase Synthesis-A Modular Building System for Combinatorial Chemistry. Angew. Chem., Int. Ed. 1999, 38, 1071-1073.

(12) (a) Effenberger, F. Diazo Chemistry I. Angew. Chem. 1995, 107, 19171918. (b) Rose, R. E. The Aromatic Diazo-Compounds and Their Technical Application (Saunders, K. H.). J. Chem. Educ. 1937, 14, 300.

(13) (a) Suleymanov, A. A.; Scopelliti, R.; Fadaei Tirani, F.; Severin, K. OnePot Synthesis of Trisubstituted Triazenes from Grignard Reagents and Organic Azides. Org. Lett. 2018, 20, 3323-3326. (b) Sieh, D. H.; Wilbur, D. J.; Michejda, C. J. Preparation of trialkyltriazenes. A comparison of the nitrogen-nitrogen bond rotation in trialkyltriazenes and aryldialkyltriazenes by variable temperature carbon-13 NMR. J. Am. Chem. Soc. 1980, 102, 38833887.

(14) Kiefer, G.; Riedel, T.; Dyson, P. J.; Scopelliti, R.; Severin, K. Synthesis of Triazenes with Nitrous Oxide. Angew. Chem., Int. Ed. 2015, 54, 302-305. (15) For reviews, see: (a) Domínguez, G.; Pérez-Castells, J. Recent advances in [2+2+2] cycloaddition reactions. Chem. Soc. Rev. 2011, 40, 3430-3444 (b) Tam, W.; Goodreid, J.; Cockburn, N. Transition Metal-Catalyzed [2 + 2] Cycloaddition Reactions between Bicyclic Alkenes and Alkynes. Curr. Org. Synth. 2009, 6, 219-238. Galan, B. R.; Rovis, T. (c) Beyond Reppe: Building Substituted Arenes by [2+2+2] Cycloadditions of Alkynes. Angew. Chem., Int. Ed. 2009, 48, 2830-2834. (d) Agenet, N.; Buisine, O.; Slowinski, F.; Gandon, V.; Aubert, C.; Malacria, M. In Organic Reactions; Overman, L. E., Ed.; John Wiley \& Sons: Hoboken, NJ, 2007, Vol. 68, pp 1- 302. (e) Chopade, P. R.; Louie, J. [2 + 2 + 2] Cycloaddition Reactions Catalyzed by Transition
Metal Complexes. Adv. Synth. Catal. 2006, 348, 2307-2327. (f) Gandon, V.; Aubert, C.; Malacria, M. Recent progress in cobalt-mediated [2+2+2] cycloaddition reactions. Chem. Commun. 2006, 2209-2217. (g) Kotha, S.; Brahmachary, E.; Lahiri, K. Transition Metal Catalyzed $[2+2+2]$ Cycloaddition and Application in Organic Synthesis. Eur. J. Org. Chem. 2005, 2005, 4741-4767. (h) Yamamoto, Y. Recent Advances in Intramolecular Alkyne Cyclotrimerization and Its Applications. Curr. Org. Chem. 2005, 9, 503-519. (i) Gandon, V.; Aubert, C.; Malacria, M. Cycloadditions, Cycloisomerizations and Related Reactions of Alkynes Bearing Group 13 or 14 Heteroelements. Curr. Org. Chem. 2005, 9, 16991712. (j) Malacria. M., Aubert. C., Renaud. J. L. in Science of Synthesis: Houben-Weyl Methods of Molecular Transformations. Lautens M., Trost B. M., Eds.; Georg Thieme Verlag: Stuttgart, 2001; Vol. 1, pp. 439-530. (k) Saito, S.; Yamamoto, Y. Recent Advances in the Transition-Metal-Catalyzed Regioselective Approaches to Polysubstituted Benzene Derivatives. Chem. Rev. 2000, 100, 2901-2916. (l) Grotjahn. D. B. In Comprehensive Organometallic Chemistry II; Abel E. W., Stone F. G. A., Wilkinson G., Hegedus L., Eds.; Pergamon: Oxford, 1995; Vol. 12, pp 741-770. (m) Boese, R.; Van Sickle, A. P.; Vollhardt, K. P. C. The Cobalt-Mediated $[2+2+2]$ Cycloaddition of $\alpha, \omega$-Diynes to the 2,3-Double Bond of Indole. Synthesis 1994, 1994, 1374-1382. (n) Schore. N. E. In Comprehensive Organic Synthesis; Trost B. M., Fleming I., Eds.; Pergamon: Oxford, 1991, Vol. 5, pp 11291162. (o) Vollhardt, K. P. C. Cobalt-Mediated [2+2+2]-Cycloadditions: A Maturing Synthetic Strategy [New Synthetic Methods (43)]. Angew. Chem., Int. Ed. 1984, 23, 539-556.

(16) For seminal reports on $[2+2+2]$ cycloadditions catalyzed by Cp*Ru(cod)Cl: (a) Yamamoto, Y.; Arakawa, T.; Ogawa, R.; Itoh, K. Ruthenium(II)-Catalyzed Selective Intramolecular $[2+2+2]$ Alkyne Cyclotrimerizations. J. Am. Chem. Soc. 2003, 125, 12143-12160. (b) Yamamoto, Y.; Hata, K.; Arakawa, T.; Itoh, K. Ru(ii)-catalyzed [2 + $2+2$ ] cycloaddition of 1,2-bis(propiolyl)benzenes with monoalkynes leading to substituted anthraquinones. Chem. Commun. 2003, 1290-1291. (c) Yamamoto, Y.; Takagishi, H.; Itoh, K. Ruthenium(II)-Catalyzed [2 + $2+2$ ] Cycloaddition of 1,6-Diynes with Tricarbonyl Compounds. J. Am. Chem. Soc. 2002, 124, 6844-6845. (d) Yamamoto, Y.; Takagishi, H.; Itoh, K. Ruthenium(II)-Catalyzed Cycloaddition of 1,6-Diynes with Isocyanates Leading to Bicyclic Pyridones. Org. Lett. 2001, 3, 2117-2119. (e) Yamamoto, Y.; Ogawa, R.; Itoh, K. Highly chemo- and regio-selective $[2+2+2]$ cycloaddition of unsymmetrical 1,6-diynes with terminal alkynes catalyzed by $\mathrm{Cp} * \mathrm{Ru}(\mathrm{cod}) \mathrm{Cl}$ under mild conditions. Chem. Commun. 2000, 549-550.

(17) For nickel-catalyzed [2 + 2+2] cycloadditions: (a) Turek, P.; Kotora, M.; Tišlerová, I.; Hocek, M.; Votruba, I.; Císařová, I. Cocyclotrimerization of 6-Alkynylpurines with $\alpha, \omega$-Diynes as a Novel Approach to Biologically Active 6-Arylpurines. J. Org. Chem. 2004, 69, 9224-9233. (b) Jeevanandam, A.; Korivi, R. P.; Huang, I. w.; Cheng, C.-H. Ni-Catalyzed Highly Regio- and Chemoselective Cocycloaddition of Nonconjugated Diynes with 1,3-Diynes: A Novel Method for Polysubstituted Arylalkynes. Org. Lett. 2002, 4, 807810. (c) Teplý, F.; Stará, I. G.; Starý, I.; Kollárovič, A.; Šaman, D.; Rulíšek, L.; Fiedler, P. Synthesis of [5]-, [6]-, and [7]Helicene via Ni(0)- or Co(I)Catalyzed Isomerization of Aromatic cis,cis-Dienetriynes. J. Am. Chem. Soc. 2002, 124, 9175-9180. (d) Duckworth, D. M.; Lee-Wong, S.; Slawin, A. M. Z.; Smith, E. H.; Williams, D. J. Co-cyclizations of nitrogen-containing acetylenes induced by a nickel triphenylphosphine complex to give aminoindane, isoindoline and isoindolinone derivatives. J. Chem. Soc., Perkin Trans. 1 1996, 815-821. (e) Sato, Y.; Nishimata, T.; Mori, M. Asymmetric Synthesis of Isoindoline and Isoquinoline Derivatives Using Nickel(0)Catalyzed [2 + $2+2$ ] Cocyclization. J. Org. Chem. 1994, 59, 6133-6135. (f) Bhatarah, P.; Smith, E. H. Oxygen ligation in the nickel-mediated [2 + 2+2] co-cyclisation of a hepta-1,6-diyne and alkynol derivatives. J. Chem. Soc., Perkin Trans. 1 1990, 2603-2606.

(18) For iron-catalyzed [2 + 2 + 2] cycloadditions: (a) Spahn, N. A.; Nguyen, M. H.; Renner, J.; Lane, T. K.; Louie, J. Regioselective Iron-Catalyzed [2 + 2 + 2] Cycloaddition Reaction Forming 4,6-Disubstituted 2-Aminopyridines from Terminal Alkynes and Cyanamides. J. Org. Chem. 2017, 82, 234-242. (b) Wang, C.; Wang, D.; Xu, F.; Pan, B.; Wan, B. Iron-Catalyzed Cycloaddition Reaction of Diynes and Cyanamides at Room Temperature. $J$. Org. Chem. 2013, 78, 3065-3072. (c) Lane, T. K.; D’Souza, B. R.; Louie, J. Iron-Catalyzed Formation of 2-Aminopyridines from Diynes and Cyanamides. J. Org. Chem. 2012, 77, 7555-7563.

(19) For palladium-catalyzed [2+2+2] cycloadditions: (a) Jayanth, T. T.; Jeganmohan, M.; Cheng, C.-H. Palladium-Catalyzed [2 + 2 + 2] Cocyclotrimerization of Benzynes with Bicyclic Alkenes: An Efficient Route to Anellated 9,10-Dihydrophenanthrene Derivatives and Polyaromatic Compounds. 
J. Org. Chem. 2004, 69, 8445-8450. (b) Sato, Y.; Tamura, T.; Mori, M. Arylnaphthalene Lignans through Pd-Catalyzed [2+2+2] Cocyclization of Arynes and Diynes: Total Synthesis of Taiwanins $\mathrm{C}$ and E. Angew. Chem., Int Ed. 2004, 43, 2436-2440. (c) Peña, D.; Pérez, D.; Guitián, E.; Castedo, L. First Partially Intramolecular Palladium-Catalyzed [2+2+2] Cycloaddition of Benzyne: Application to the Synthesis of Benzo[b]fluorenones. Eur. J. Org. Chem. 2003, 2003, 1238-1243. (d) Gevorgyan, V.; Radhakrishnan, U.; Takeda, A.; Rubina, M.; Rubin, M.; Yamamoto, Y. Palladium-Catalyzed Highly Chemo- and Regioselective Formal [2 + $2+2]$ Sequential Cycloaddition of Alkynes: A Renaissance of the Well Known Trimerization Reaction? J. Org. Chem. 2001, 66, 2835-2841. (e) Gevorgyan, V.; Takeda, A.; Yamamoto, Y. First Intermolecular Regiospecific Palladium-Catalyzed Enyne-Diyne [4 + 2] Cross-Benzannulation Reaction. J. Am. Chem. Soc. 1997, 119, 11313-11314.

(20) For reviews, see: (a) Heller, B.; Hapke, M. The fascinating construction of pyridine ring systems by transition metal-catalysed [2+2+2] cycloaddition reactions. Chem. Soc. Rev. 2007, 36, 1085-1094. (b) Varela, J. A.; Saá, C. Construction of Pyridine Rings by Metal-Mediated [2+2+2] Cycloaddition. Chem. Rev. 2003, 103, 3787-3802.

(21) For [2 + 2+2] cycloadditions with tethered alkynyl nitriles: (a) You, X.; Xie, X.; Wang, G.; Xiong, M.; Sun, R.; Chen, H.; Liu, Y. Nickel-Catalyzed $[2+2+2]$ Cycloaddition of Alkyne-Nitriles with Alkynes Assisted by Lewis Acids: Efficient Synthesis of Fused Pyridines. Chem. - Eur. J. 2016, 22, 16765-16769. (b) D’Souza, B. R.; Lane, T. K.; Louie, J. Iron-Catalyzed Cycloaddition of Alkynenitriles and Alkynes. Org. Lett. 2011, 13, 2936. (c) Zhou, Y.; Porco, J. A.; Snyder, J. K. Synthesis of 5,6,7,8-Tetrahydro-1,6naphthyridines and Related Heterocycles by Cobalt-Catalyzed [2+2+2] Cyclizations. Org. Lett. 2007, 9, 393-396. (d) Young, D. D.; Deiters, A. A General Approach to Chemo- and Regioselective Cyclotrimerization Reactions. Angew. Chem., Int. Ed. 2007, 46, 5187-5190. (e) Varela, J. A.; Castedo, L.; Saá, C. One-Step Synthesis of Symmetrical 3,3'-Substituted 2,2' Bipyridine Ligands by Cobalt(I)-Catalyzed [2+2+2] Cycloadditions. J. Am. Chem. Soc. 1998, 120, 12147-12148. (f) Varela, J. A.; Castedo, L.; Saá, C. Synthesis of Annelated Substituted Bipyridines and Terpyridines by Cobalt(I)-Catalyzed [2 + 2 + 2] Cycloaddition. J. Org. Chem. 1997, 62, 41894192. (g) Brien, D. J.; Naiman, A.; Vollhardt, K. P. C. Catalytic co-cyclisation of $\alpha, \omega$-cyanoalkynes with alkynes: a versatile chemo- and regio-selective synthesis of 2,3-substituted 5,6,7,8-tetrahydroquinolines and other cycloalka[1,2-b]pyridines. J. Chem. Soc., Chem. Commun. 1982, 133-134. (22) For ruthenium-catalyzed pyridine synthesis: (a) Bhatt, D.; Patel, N.; Chowdhury, H.; Bharatam, P. V.; Goswami, A. Additive-Controlled Switchable Selectivity from Cyanobenzenes to 2-Alkynylpyridines: Ruthenium(II)-Catalyzed [2 + 2 + 2] Cycloadditions of Diynes and Alkynylnitriles. Adv. Synth. Catal. 2018, 360, 1876-1882. (b) Ye, F.; Haddad, M.; Ratovelomanana-Vidal, V.; Michelet, V. Ruthenium-Catalyzed [2 + $2+$ 2] Cycloaddition Reaction Forming 2-Aminopyridine Derivatives from $\alpha, \omega-$ Diynes and Cyanamides. Org. Lett. 2017, 19, 1104-1107. (c) Medina, S.; Domínguez, G.; Pérez-Castells, J. Efficient Generation of Pyridines by Ruthenium Carbene Mediated [2 + 2 + 2] Cyclotrimerization. Org. Lett. 2012, 14, 4982-4985. (d) Xu, F.; Wang, C.; Li, X.; Wan, B. Ruthenium-catalyzed $[2+2+2]$ Cycloaddition of Diynes with Nitriles in Pure Water. ChemSusChem 2012, 5, 854-857. (e) Yamamoto, Y.; Kinpara, K.; Ogawa, R.; Nishiyama, H.; Itoh, K. Ruthenium-Catalyzed Cycloaddition of 1,6-Diynes and Nitriles under Mild Conditions: Role of the Coordinating Group of Nitriles. Chem. - Eur. J. 2006, 12, 5618-5631. (f) Yamamoto, Y.; Kinpara, K.; Saigoku, T.; Takagishi, H.; Okuda, S.; Nishiyama, H.; Itoh, K. Cp*RuCl-Catalyzed [2 + $2+2]$ Cycloadditions of $\alpha, \omega$-Diynes with Electron-Deficient Carbon-Heteroatom Multiple Bonds Leading to Heterocycles. J. Am. Chem. Soc. 2005, 127, 605613. (g) Varela, J. A.; Castedo, L.; Saá, C. Scope of Ru(II)-Catalyzed Synthesis of Pyridines from Alkynes and Nitriles. J. Org. Chem. 2003, 68 , 8595-8598. (h) Yamamoto, Y.; Okuda, S.; Itoh, K. Ruthenium(ii)-catalyzed $[2+2+2]$ cycloaddition of 1,6-diynes with electron-deficient nitriles. Chem. Commun. 2001, 1102-1103. (i) Yamamoto, Y.; Ogawa, R.; Itoh, K. Significant Chemo- and Regioselectivies in the Ru(II)-Catalyzed [2 + 2 + 2] Cycloaddition of 1,6-Diynes with Dicyanides. J. Am. Chem. Soc. 2001, 123, 6189-6190.

(23) (a) Wezeman, T.; Scopelliti, R.; Tirani, F. F.; Severin, K. Synthesis of Heteroaryl Triazenes via Rh(III)-catalyzed Annulation Reactions with Alkynyl Triazenes. Adv. Synth. Catal. 2019, 361, 1383-1388. (b) Suleymanov, A. A.; Scopelliti, R.; Tirani, F. F.; Severin, K. Synthesis of Vinyl Triazenes by Palladium-Catalyzed Addition Reactions to Alkynyl Triazenes. Adv. Synth. Catal. 2018, 360, 4178-4183. (c) Kossler, D.; Perrin, F. G.; Suleymanov, A. A.; Kiefer, G.; Scopelliti, R.; Severin, K.; Cramer, N. Divergent Asymmetric
Synthesis of Polycyclic Compounds via Vinyl Triazenes. Angew. Chem., Int. Ed. 2017, 56, 11490-11493. (d) Jeanbourquin, L. N.; Scopelliti, R.; Tirani, F. F.; Severin, K. Gold-Catalyzed Synthesis of 1,3-Diaminopyrazoles from 1Alkynyltriazenes and Imines. Helv. Chim. Acta 2017, 100, e1700186. (e) Jeanbourquin, L. N.; Scopelliti, R.; Fadaei Tirani, F.; Severin, K. Synthesis and Reactivity of 1-Allenyltriazenes. Org. Lett. 2017, 19, 2070-2073. (f) Perrin, F. G.; Kiefer, G.; Jeanbourquin, L.; Racine, S.; Perrotta, D.; Waser, J.; Scopelliti, R.; Severin, K. 1-Alkynyltriazenes as Functional Analogues of Ynamides. Angew. Chem., Int. Ed. 2015, 54, 13393-13396.

(24) (a) Schlosser, M.; Ruzziconi, R. Nucleophilic Substitutions of Nitroarenes and Pyridines: New Insight and New Applications. Synthesis 2010 2010, 2111-2123. (b) Crampton, M. R. In Organic Reaction Mechanisms; Knipe A. C., Watts W. E., Eds.; Wiley: Chichester, 2003; pp 275-286. (c) Spitzner, D. In Houben-Weyl: Methoden der Organischen Chemie; Kreher R. P., Eds.; Thieme: Stuttgart, 1992; Vol. E7b, pp 604-625. (d) Duffy, J. L.; Laali, K. K. Aprotic Nitration $\left(\mathrm{NO}_{2}{ }^{+} \mathrm{BF}_{4}{ }^{-}\right.$, Nitryl Tetrafluoroborate) of 2-Haloand 2,6-Dihalopyridines and Transfer-nitration Chemistry of Their N-nitropyridinium Cations. J. Org. Chem. 1991, 56, 3006-3009. (e) Jephcott, C. M. Friedel and Crafts' Reaction in the Pyridine Series. J. Am. Chem. Soc. 1928, $50,1189-1192$.

(25) (a) Kormos, C. M.; Ondachi, P. W.; Runyon, S. P.; Thomas, J. B.; Mascarella, S. W.; Decker, A. M.; Navarro, H. A.; Fennell, T. R.; Snyder, R. W.; Carroll, F. I. Potent and Selective Tetrahydroisoquinoline Kappa Opioid Receptor Antagonists of Lead Compound (3R)-N-[1R)-1(Cyclohexylmethyl)-2-methylpropyl]-7-hydroxy-1,2,3,4 tetrahydroisoquinoline-3-carboxamide (CDTic). J. Med. Chem. 2018, 61, 7546-7559. (b) Tiong, S. H.; Looi, C. Y.; Arya, A.; Wong, W. F.; Hazni, H.; Mustafa, M. R.; Awang, K. Vindogentianine, a hypoglycemic alkaloid from Catharanthus roseus (L.) G. Don (Apocynaceae). Fitoterapia 2015, 102, 182-188. (c) Opperman, T. J.; Kwasny, S. M.; Kim, H.-S.; Nguyen, S. T.; Houseweart, C.; Souza, S.; Walker, G. C.; Peet, N. P.; Nikaido, H.; Bowlin, T. L. Characterization of a Novel Pyranopyridine Inhibitor of the AcrAB Efflux Pump of the AcrAB efflux pump of Escherichia coli. Antimicrob. Agents Chemother. 2014, 58, 722733. (d) Fenical, W.; Jensen, P. R. Developing a new resource for drug discovery: marine actinomycete bacteria. Nat. Chem. Biol. 2006, 2, 666-673. (e) Severina, I. S.; Pyatakova, N. V.; Postnikov, A. B.; Preobrazhenskaya, M. N.; Khropov, Y. V. Antitumor antibiotic streptonigrin and its derivatives as inhibitors of nitric oxide-dependent activation of soluble guanylyl cyclase. Eur. J. Pharmacol. 2004, 483, 127-132. (f) Papageorgiou, M.; Fokialakis, N.; Mitaku, S.; Skaltsounis, A.-L.; Tillequin, F.; Sévenet, T. Two New Alkaloids from the Bark of Sarcomelicope megistophylla. J. Nat. Prod. 2000, 63, 385386. (g) Yamada, O.; Ogasawara, K. Asymmetric synthesis of sceletium alkaloids: (-)-mesembrine, (+)-sceletium A-4, (+)-tortuosamine and (+)-Nformyltortuosamine. Tetrahedron Lett. 1998, 39, 7747-7750.

(26) (a) Carbó, J. J.; Crochet, P.; Esteruelas, M. A.; Jean, Y.; Lledós, A.; López, A. M.; Oñate, E. Two- and Four-Electron Alkyne Ligands in Osmium-Cyclopentadienyl Chemistry: Consequences of the $\pi \rightarrow \mathrm{M}$ Interaction. Organometallics 2002, 21, 305-314. (b) Templeton, J. L.; Ward, B. C. Carbon-13 Chemical Shifts of Alkyne Ligands as Variable Electron Donors in Monomeric Molybdenum and Tungsten Complexes. J. Am. Chem. Soc. 1980, 102, 3288-3290.

(27) (a) Roşca, D.-A.; Radkowski, K.; Wolf, L. M.; Wagh, M.; Goddard, R.; Thiel, W.; Fürstner, A. Ruthenium-Catalyzed Alkyne trans-Hydrometalation: Mechnistic Insights and Preparative Implications. J. Am. Chem. Soc. 2017, 139, 2443-2455. (b) Rummelt, S. M.; Radkowski, K.; Roşca, D.-A.; Fürstner, A. Interligand Interactions Dictate the Regioselectivity of transHydrometalations and Related Reactions Catalyzed by [Cp*RuCl]. Hydrogen Bonding to a Chloride Ligand as a Steering Principle in Catalysis. J. Am. Chem. Soc. 2015, 137, 5506. (c) Dutta, B.; Curchod, B. F. E.; Campomanes, P.; Solari, E.; Scopelliti, R.; Rothlisberger, U.; Severin, K. Reactions of Alkynes with [RuCl(cyclopentadienyl)] Complexes: The Important First Steps. Chem. Eur. J. 2010, 16, 8400-8409.

(28) CCDC 1909133, 1909134 and 1909135 contain the supplementary crystallographic data for this paper. These data can be obtained free of charge from The Cambridge Crystallographic Data Centre via www.ccdc.cam.ac.uk/data_request/cif.

(29) (a) Shvydkiy, N. V.; Perekalin, D. S. Cyclobutadiene complexes of platinum metals. Coord. Chem. Rev. 2017, 349, 156-168. (b) Le Paih, J.; Dérien, S.; Demerseman, B.; Bruneau, C.; Dixneuf, P. H.; Toupet, L.; Dazinger, G.; Kirchner, K. Ruthenium-Catalyzed Synthesis of Alkylidenecyclobutenes via Head-to-Head Dimerization of Propargylic Alcohols and Cyclobutadiene-Ruthenium Intermediates. Chem. Eur. J. 2005, 
11, 1312-1324. (c) Le Paih, J.; Dérien, S.; Bruneau, C.; Demerseman, B.; Toupet, L.; Dixneuf, P. H. Ruthenium-Catalyzed One-Step Transformation of Propargylic Alcohols into Alkylidene Cyclobutenes: X-ray Characterization of an $\mathrm{Ru}\left(\eta^{3}\right.$-cyclobutenyl) Intermediate. Angew. Chem. Int. Ed. 2001, 40, 2912-2915.

(30) (a) Ji, X.; Yang, D.; Tong, P.; Li, J.; Wang, B.; Qu, J. C-H Activation of Cp* Ligand Coordinated to Ruthenium Center: synthesis and Reactivity of a Thiolate-Bridged Diruthenium Complex Featuring Fulvene-like Cp* Ligand. Organometallics 2017, 36, 1515-1521. (b) Li, S.; Wang, X.; Zhang, Z.; Zhao, Y.; Wang, X. Isolation and structural characterization of a mainly ligandbased dimetallic radical. Dalton Trans. 2015, 44, 19754-19757. (c) Hashimoto, H.; Tobita, H.; Ogino, H. Synthesis, structure, and fluxional behavior of 1,2,3,4-tetramethylfulvene-bridged diruthenium complexes. Inorg. Chim. Acta 2003, 350, 347-354. (d) Ho, E. N.-M.; Lin, Z.; Wong, W.T. Synthesis, Characterization, Crystal Structures, Reactivity, and Elecrochemistry of Rurthenium - Nitrido, Ruthenium - Cobalt - Imido and Ruthenapyrrolidone Carbonly Clusters Containing Alkyne Ligands. Chem. Eur. J. 2001, 7, 258-271. (e) Kaganovich, V. S.; Rybinskaya, M. I.; Kerzina, Z. A.; Dolgushin, F. M.; Yanovsky, A. I.; Struchkov, Y. T.; Petrovskii, P. V.; Kolehmainen, E.; Kivikoski, J.; Valkonen, J.; Laihia, K. Cyclopentadienyl derivatives of octahedral carbonylcarbide hexaruthenium clusters: synthesis, NMR, IR and X-ray characterization. J. Organomet. Chem. 1996, 518, 115119 . 


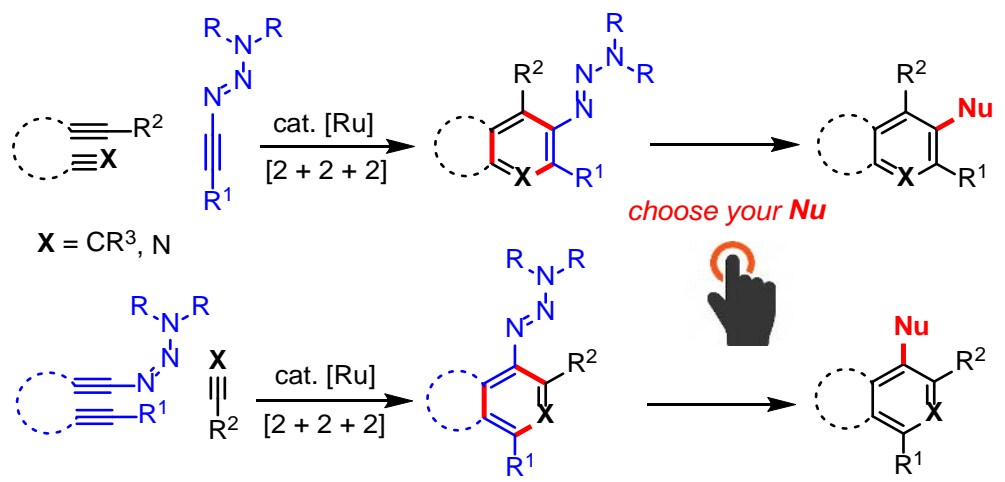

